\title{
How polarized are online and offline news audiences? A comparative analysis of twelve countries
}

\author{
Richard Fletcher ${ }^{\text {a }}$, Alessio Cornia ${ }^{\text {ba }}$, and Rasmus Kleis Nielsen ${ }^{\text {a }}$ \\ ${ }^{a}$ Reuters Institute for the Study of Journalism, Department of Politics and International \\ Relations, University of Oxford \\ ${ }^{b}$ Department of Communications, Dublin City University
}

Polarization is a key area of interest for media and communication scholars. We develop a way of measuring how polarized news audiences are at the national level. Then, we analyse survey data from 12 countries and find: (i) that cross-platform (online and offline) news audience polarization is highest in the USA, and within Europe, higher in polarized pluralist/southern countries than in democratic corporatist countries. Furthermore, (ii) in most countries online news audience polarization is higher than offline, but in a small number it's lower. Taken together our findings highlight that, despite the well-documented fears associated with algorithmic selection, news audience polarization is not inevitable in environments that are increasingly characterised by digital news consumption, and that the historical, economic and political factors emphasised by the comparative tradition remain critically important for our understanding of global trends.

We aim to address three key questions facing media and communication researchers today. First, to what extent is news audience behaviour politically polarized? Second, how does polarization vary country-to-country? And third, is online news audience behaviour more polarized than offline news audience behaviour? 
Previous research has shown that people engage in partisan selective exposure, where they are more likely to choose to consume news from sources aligned with their political views (Iyengar and Hahn 2009; Stroud 2011). Studies have also shown that the extent to which national news media parallel the political structure can vary, with some countries exhibiting higher levels of 'political parallelism' than others (Hallin and Mancini 2004; Brüggemann et al. 2014). If viewed together, these findings suggest that we should see relatively polarized patterns of news audience behaviour in some countries, but not in others. However, as yet, we lack a measure that allows us to put this to the test.

A further key issue is whether the growth of digital media, and the accompanying expansion in media choice, has created online news audiences that are more polarized than offline news audiences. Early studies on the growth of online news consumption in the USA seemed to support this idea (Iyengar and Hahn 2009; Stroud 2011), and concerns have since been intensified by the popular notion that algorithmic news selection might trap people inside echo chambers and filter bubbles (Sunstein 2017; Pariser 2011). Others, however, have pushed back, arguing that polarization is not inevitable if people increasingly spread their news consumption across multiple outlets (Webster and Ksiazek 2012; Nelson and Webster 2017; Fletcher and Nielsen 2017), or if algorithms actually expose people to sources of news they would not otherwise use (Weeks et al. 2017; Fletcher and Nielsen 2018).

Because much recent research on news audience behaviour and the implications of the move to a more digital media environment has been based on data from the USA, we still know little about how it differs across countries with different media systems. We aim to address this by developing an audience-centric (Webster and Ksiazek 2012) measure of the degree of left-right news audience polarization across different countries and different media platforms (print, broadcast, and online). We use the term 'news audience polarization' to refer to the extent to which countries are home to large news outlets with both strongly left- 
and strongly right-leaning audiences, as opposed to outlets with mostly mixed or centrist audiences.

Using data from the 2017 Reuters Institute Digital News Report (Newman et al. 2017) in 12 countries (USA, UK, Australia, Ireland, France, Italy, Spain, Germany, Netherlands, Finland, Poland, Czech Republic), we first measure the political leaning of audiences for individual news outlets, before presenting a way of visualizing the results on a country-bycountry basis. We then use this data to produce an aggregate measure of news audience polarization that can be applied to different countries and different platforms.

We find, first, that the degree of cross-platform news audience polarization is higher in European countries with polarized pluralist/southern media systems than in countries with democratic corporatist media systems. However, news audience polarization was highest of all in the USA. Second, despite fears over highly polarized online media environments, we find that in most cases online news audience polarization currently differs little from offline news audience polarization. In eight of the countries we analyse, online news audience polarization is indeed slightly higher than offline news audience polarization, but in the four others, online news audience polarization is in fact lower.

Taken together, the results highlight the importance of approaching questions around news audience behaviour using a comparative perspective, and caution against treating the USA - by far the most polarized of the 12 countries according to our results - as a microcosm of the rest of the world. They also show that news audience polarization is not inevitable in environments increasingly characterized by digital consumption, and that the historical, economic and political factors emphasised by the comparative tradition remain critically important. 


\section{Polarization}

Polarization is very widely-discussed in the academic literature, and has been deployed as a concept in many different ways. In the USA - the source of much research on the topicthere is clear evidence that political elites are increasingly polarized (Hetherington 2009), but when it comes to the mass public, the picture is more complicated because different measures and conceptualizations of polarization tend to produce different results. Research into 'ideological' polarization has looked at both the extent to which people consistently align themselves with a particular side, as well as the extent to which their ideologies diverge. Scholars have also studied 'affective' polarization, referring to the extent to which opposing partisans dislike one another, and 'perceived' polarization, which focusses on people's perceptions of the level of polarization in society (see Lelkes 2016 for an overview).

Research has explored how each of these conceptualizations of polarization has been influenced by the news media (e.g. Prior 2013; Garrett et al. 2014; Yang et al. 2016). But we might also ask about the extent to which news use itself has become ideologically polarized. Here, then, we are interested in news audience polarization, which we use to refer to the extent to which people form audiences for news outlets that are either strongly left-leaning or strongly right-leaning.

\section{Selective exposure}

A clear starting point for thinking about news audience polarization is selective exposure.

This is the simple idea that, all else being equal, people will self-select news media based on their beliefs and/or interests. This idea has a long history in communication research, but recent studies have focussed on the impact of technological change, in particular the consequences of the shift towards high-choice media environments. Iyengar and Hahn (2009) observed that the trend towards a more divided electorate in the USA occurred 
simultaneously with the explosion of digital media and cable television, and found strong evidence that people selected news outlets based on their political views. Stroud (2011) also found evidence of increased partisan selective exposure, observing that as the number of alternative sources of information increased, people became more likely to choose news outlets that support their beliefs and opinions. Experimental studies tend to find similar effects, but perhaps surprisingly, partisan selective exposure does not necessarily lead to more polarized political attitudes for most people (Arceneaux, Johnson, and Cryderman 2013; Trilling, van Klingeren, and Tsfati 2017). And more recently, researchers have produced evidence that seems to downplay the extent of partisan selective exposure. Nelson and Webster's (2017) analysis of Comscore tracking data found that, despite huge choice, most people tend to congregate around a few popular news outlets, and that all news sitesincluding partisan ones — attract ideologically diverse audiences.

Many of the more recent studies of selective exposure have focussed on the use of social media - prompted by widespread concerns over echo chambers, filter bubbles, and more broadly, the consequences of the move to algorithmically-driven information environments (Bakshy, Messing, and Adamic 2015; Flaxman, Goel, and Rao 2016). However, most of these studies find little evidence of pervasive echo chambers (Dubois and Blank 2018) or filter bubbles (Zuiderveen Borgesius et al. 2016), suggesting that the potential impact on polarization is small. Indeed, it has been shown elsewhere that social media is associated with incidental exposure to news, meaning that people who mostly use social media for other reasons nonetheless see news from sources they wouldn't otherwise use. This could expand people's news repertoires, exposing them to a broader range of sources on average than people who do not use social media at all (Fletcher and Nielsen 2018).

Selective exposure to news does not have to be shaped by politics. Markus Prior has repeatedly emphasised the importance of people's relative preference for entertainment over 
politics for understanding news selection (Prior 2005). Studies from Europe in particular have found that whilst people do select media based on their left-right preferences, levels of

political interest ultimately seem to matter more (Skovsgaard, Shehata, and Strömbäck 2016). This might suggest that news audience polarization is generally lower in Europe than in the USA. Furthermore, the importance of political interest is lower in countries with popular public service media, as they are more likely to show news at primetime, and thus more likely to reach people who lack the motivation to seek out news for themselves (CastroHerrero, Nir, and Skovsgaard 2018).

\section{Political parallelism}

One way of thinking about how the influence of partisan selective exposure might vary in different parts of the world is through the concept of political parallelism. In Comparing Media Systems, Hallin and Mancini (2004) saw political parallelism as one of the key variables for differentiating media systems in Western countries. Since one-to-one connections between news outlets and specific political parties are relatively uncommon today, they used political parallelism to refer to the ideological alignment between news outlets and "general political tendencies" or political camps (Hallin and Mancini 2004, 27).

For Hallin and Mancini, political parallelism is manifest in phenomena like the political affiliations of journalists and the slant of media content. But more relevantly for our purposes here, political parallelism can also be evident in partisan news consumption patterns, or, how audiences with distinct political ideologies tend to gravitate towards particular outlets (Hallin and Mancini 2016). As such, news audience polarization could be seen as a component of political parallelism, but political parallelism refers to a broader set of phenomena, and they are not synonymous. However, given that there is at least some overlap 
between the two, it should be possible to use insights from the comparative tradition to guide our expectations about news audience polarization.

Hallin and Mancini's (2004) original analysis placed 18 countries into one of three media system ideal types: (i) polarized pluralist (France, Greece, Italy, Portugal, Spain), (ii) democratic corporatist (Austria, Belgium, Denmark, Finland, Germany, Netherlands, Norway, Sweden, Switzerland), and (iii) liberal (UK, USA, Ireland, Canada). They argued that polarized pluralist media systems are marked by high levels of political parallelism, democratic corporatist media systems by historically-high-but-declining levels, and liberal media systems by low levels. However, more recent attempts to empirically validate these claims have showed different patterns. Brüggemann et al.'s (2014) quantitative operationalization of Hallin and Mancini's criteria led them to develop their own media system typology, grouping together (i) northern (Denmark, Finland, Norway, Sweden), (ii) central (Austria, Switzerland, Germany, UK), (iii) western (Belgium, Ireland, Netherlands, Portugal, USA), and (iv) southern (Spain, France, Greece, Italy) countries. They found that political parallelism was highest of all in the southern countries, lowest in the northern countries, with western and central countries exhibiting similarly moderate levels.

Again, it is crucial to keep in mind that Brüggemann et al.'s (2014) operationalization of political parallelism was based on more than audience behaviour. They also incorporated measures of the separation of news and commentary, policy advocacy, journalist ideology, political bias, and public service media independence. Indeed, these five indicators are fundamentally different in that they relate to news production and news content, rather than audience behaviour. As such, studies that have understood political parallelism primarily through audience behaviour are more relevant for our purposes here.

One such study comes curtesy of van Kempen (2007), who used data from the European Election Study to examine 'media-party parallelism', or, the strength of the 
association between respondents' identification with political parties and their use of particular news outlets. As we might expect from other work, polarized pluralist countries like Greece, Italy and Spain showed the highest levels of parallelism, and democratic corporatist countries like Germany and Finland were among the lowest. There were only two liberal countries in the sample, with Ireland showing the second lowest levels of parallelism, and Britain ranking seventh out of sixteen.

Table 1. Political parallelism and media-party parallelism by country

\begin{tabular}{|c|c|c|c|c|c|}
\hline \multirow[b]{2}{*}{ Country } & \multirow{2}{*}{$\begin{array}{c}\text { Political parallelism: } \\
\text { Hallin and Mancini (2004) } \\
\text { Category }\end{array}$} & \multicolumn{2}{|c|}{$\begin{array}{c}\text { Political parallelism: } \\
\text { Brüggemann et al. (2014) }\end{array}$} & \multicolumn{2}{|c|}{$\begin{array}{l}\text { Media-party parallelism: } \\
\text { van Kempen (2007) }\end{array}$} \\
\hline & & Score & Rank & Score & Rank \\
\hline Greece & High & 1.43 & 3 & 19.9 & 1 \\
\hline Italy & High & 1.74 & 2 & 14.4 & 2 \\
\hline Spain & High & 2.10 & 1 & 10.5 & 3 \\
\hline Denmark & High-but-declining & -1.32 & 16 & 9.1 & 5 \\
\hline France & High & 0.62 & 4 & 7.5 & 6 \\
\hline UK & Low & -0.29 & 10 & 7.1 & 7 \\
\hline Sweden & High-but-declining & -0.39 & 11 & 6.8 & 8 \\
\hline Portugal & High & -0.08 & 8 & 6.2 & 9 \\
\hline Netherlands & High-but-declining & 0.19 & 6 & 5.7 & 10 \\
\hline Austria & High-but-declining & 0.35 & 5 & 5.3 & 11 \\
\hline Luxembourg & - & - & - & 4.5 & 12 \\
\hline Finland & High-but-declining & -1.36 & 17 & 1.8 & 14 \\
\hline Ireland & Low & -0.06 & 7 & 1.6 & 15 \\
\hline Germany & High-but-declining & -0.56 & 13 & 1.0 & 16 \\
\hline USA & Low & -0.12 & 9 & - & - \\
\hline Switzerland & High-but-declining & -0.50 & 12 & - & - \\
\hline Belgium & High-but-declining & -0.70 & 14 & - & - \\
\hline Norway & High-but-declining & -1.04 & 15 & - & - \\
\hline Canada & Low & - & - & - & - \\
\hline
\end{tabular}

Note. Van Kempen did not provide a figure for Belgium because Flanders and Wallonia were analysed separately (ranking $4^{\text {th }}$ and $13^{\text {th }}$ respectively).

The results from all three aforementioned studies are summarised in Table 1.

Glancing at this table, it is initially difficult to spot clear patterns. However, one consistent pattern that is visible across all three studies is the high level of parallelism in the polarized pluralist/southern countries, in particular Greece, Italy, Spain and France. At the same time, it is also true that some of the democratic corporatist countries, namely Germany and Finland, 
display low levels of political parallelism and media-party parallelism. But there are also obvious inconsistencies. Denmark, for example, has the fifth highest level of media-party parallelism, but the second lowest level of political parallelism. There is also missing data. In particular, a measure of media-party parallelism — the most relevant measure for our purposes here - is only available for two countries from the liberal model, making it difficult to form expectations about news audience polarization.

Though media-party parallelism is the most relevant concept, the survey data on which van Kempen's study was based was collected in 1999, and thus limited to legacy media. Van Kempen extended previous work by examining television as well as the printed press, but we have now reached the stage where online news access is so widespread that it should also be considered. Not only has the internet allowed many new 'digital-born' news sources to enter media systems, but — as we have seen from research into selective exposure — online news access is fundamentally different from traditional access, with possible implications for news audience polarization.

On this basis, our aim here is to build on research into selective exposure and political parallelism to define a measure of news audience polarization that is: (i) quantitative, (ii) comparable across countries, (iii) cross-platform, and (iv) audience-centric. Building on the approach developed by James G. Webster and his collaborators (Webster and Ksiazek 2012), we depart from measures that are media-centric (e.g. differences between outlets) or usercentric (differences between individuals) by instead taking the audience as the unit of analysis, and focussing on the patterns that exist between news audiences across the media system as a whole. As stated earlier, the term 'news audience polarization' refers to the extent to which a given media system contains news outlets with both strongly left- and strongly right-leaning audiences. Put differently, a low news audience polarization score would indicate that a media system contains many outlets with a roughly equal mixture of left- and 
right-leaning and/or centrist people, whereas a high polarization score would indicate that audiences are strongly left- or right-leaning.

Placing our unit of analysis at this aggregate level allows us to compare across national contexts, responding to frequent calls for a greater emphasis on audiences in comparative media research (e.g. Blumler and Gurevitch 1995). ${ }^{1}$ We can then use these measures to shed light on some of the most fundamental questions concerning news audience polarization, namely how it differs across countries, and whether it is stronger offline or online.

\section{Hypotheses}

As we have seen, previous cross-national studies of political parallelism and media-party parallelism have produced conflicting results. But they do tend to suggest that parallelism is lower in countries originally classified as democratic corporatist, and higher in countries classified as polarized pluralist/southern. Although parallelism and news audience polarization are not the same, we can still hypothesize (H1) that democratic corporatist countries will exhibit lower levels of news audience polarization than polarized pluralist/southern countries.

H1: Cross-platform (online and offline) news audience polarization will be higher in countries with polarized pluralist/southern media systems than in countries with democratic corporatist media systems.

\footnotetext{
${ }^{1}$ For this paper, we do not consider studies that use content analysis of media outputs to measure political parallelism and similar concepts (e.g. Esser and Umbricht 2013).
} 
This leads us to an important point, namely that some countries-particularly those in the liberal model — are often considered hybrid cases, more accurately positioned in-between different models, or marked by significant ongoing changes. The UK is considered a hybrid case because of its printed press, which is generally seen as more partisan than in other liberal countries (Hallin and Mancini 2004). Additionally, some have argued that the US media system is moving towards an increasingly partisan media landscape, marked by a stronger divide between 'red' and 'blue' media, and a more divided political culture due to greater ideological divergence among voters (Levendusky 2013; Pew 2014). The extent of this shift has prompted scholars to rethink the place of the USA within traditional typologies. Nechushtai (2018), for example, observes increased competition and increased politicization of news content, funding, and consumption, and suggests that the American media system is drifting away from the liberal model into a new category of 'polarized liberal'. As a result, we do not have clear expectations about news audience polarization in liberal media systems, so we explore this using a research question.

RQ1. What is the extent of news cross-platform news audience polarization in countries with liberal media systems?

Our second aim is to explore within-country differences between online and offline news audience polarization. As we noted earlier, scholars writing about the USA in the first decade of the twenty-first century found that the move to an increasingly digital, and increasingly high-choice news media environment increased partisan selective exposure, and thus news audience polarization (e.g. Iyengar and Hahn 2009). However, it is also important to note that the effects in Europe were typically weaker, and that some have downplayed the prevalence of partisan selective exposure. 
This provides an indication of what changes to expect on what we might call the 'demand' side, but we also have to consider changes to the 'supply' of news. Here, it is generally accepted that in many countries reduced barriers-to-entry have allowed more partisan 'digital-born' brands (without a print or broadcast legacy) to enter media systems. Research on these new digital-born outlets is still emerging, but based on what we know about selective exposure, we should expect their audiences to be highly partisan, but small (Newman et al. 2018). Although studies of partisan media more broadly have shown how they can indirectly polarize political attitudes by influencing elite discourse (Levendusky 2013), their small audience size means that we do not expect them to have a large influence on the difference between online and offline news audience polarization at the national level.

Furthermore, although some digital-born brands are undoubtedly partisan, we should not underestimate the impact of other digital-born brands that either have a broadly centrist slant, or attract large and diverse audiences because they aggregate content from a range of other outlets. Often overlooked by scholars are those outlets that emerged in the late 1990s and early 2000s as web portals, placing aggregated news alongside other essential web services like search and email. Research from countries where web portals remain popularsuch as Japan- - has shown that they can incidentally expose people to news, as they are shown information they did not seek out (Kobayashi and Inamasu 2015). Because current evidence is mixed, we have no clear expectations about differences between levels of online and offline news audience polarization. We therefore ask the following research question:

RQ2: Is online news audience polarization higher than offline news audience polarization? 


\section{Measures}

Data

We address these hypotheses with data from the 2017 Reuters Institute Digital News Report survey (Newman et al. 2017). The survey was conducted by YouGov in partnership with the Reuters Institute for the Study of Journalism at the University of Oxford during late January and early February 2017. An online questionnaire was used to survey over 70,000 respondents across a total of 36 markets. Samples were drawn from YouGov's panels (and those of their partners) within each market, and respondents were invited to complete the survey in order to meet interlocking quotas for age, gender, and region. Respondents who said they use news less than once a month were filtered out at an early stage of the survey.

Most previous studies in this area are based on survey data because it is difficult to collect data about political preferences in any other way. Surveys are also well suited for the collection of single-source data on cross-platform media use. Specific strengths associated with this dataset include, first, the fact that the survey captured data using the same questions at the same point in time across a range of different markets, thus affording a truly comparative analysis. Second, respondents within each market were asked about their use of particular news outlets both online and offline, allowing us to compare across platforms and to combine online and offline measures to understand cross-platform use. Lastly, in contrast to much tracking data, the survey aimed to measure - and specifically asked about—news use via mobile browsers, apps and social media, rather than just desktop website access.

\section{Country selection}

We analyse data from a strategic sample 12 countries picked from the available 36 markets. They are: USA, UK, Australia, Ireland, France, Italy, Spain, Germany, Netherlands, Finland, Poland, Czech Republic $(\mathrm{N}=24,485)$. Our selection was primarily informed by Hallin and 
Mancini's (2004) three media system models: (i) polarized pluralist, and (ii) democratic corporatist, and (iii) liberal. Hallin and Mancini originally analysed 18 countries and placed each of them into one of the three models. We picked three from each model, and then an additional three that Hallin and Mancini did not classify.

Country selection was primarily informed by population size, geographic region within each model, whether they are home to multiple media systems based on language, and whether they are likely to be an interesting or extreme case. Hallin and Mancini placed four countries into their liberal model: UK, USA, Ireland and Canada. It was not possible for us to analyse Canada using our approach because it is essentially home to two media systems, one based on French-language media and one based on English-language media. This left only three countries: UK, USA and Ireland. The polarized pluralist model has five members: France, Greece, Italy, Portugal, and Spain. We selected France, Italy, and Spain because of their much larger populations. The democratic corporatist model was the largest of the three models, with nine members: Austria, Belgium, Denmark, Finland, Germany, Netherlands, Norway, Sweden, and Switzerland. Belgium and Switzerland were excluded because, like Canada, they are home to multiple language-based media systems. Germany and the Netherlands were chosen because of their larger populations. Following Brüggemann et al.'s (2014) identification of a northern media system, we thought it sensible for the other country to be from the Nordic region, so we chose Finland.

We also recognised the opportunity to include three countries that have not been extensively studied in comparative media research. We chose three that we thought we could reasonably interpret alongside the other nine. We picked Australia because we felt it was comparable to countries in the liberal model, as they share elements of language and culture. We chose Poland and the Czech Republic because of their relatively large populations (especially Poland) and because it would be possible to compare them to the polarized 
pluralist/southern countries to some extent (Hallin and Mancini 2013). The countries included are listed in Table 2, along with descriptive statistics of the sample in each, such as average age, proportion of male respondents, and so on.

Table 2. Descriptive statistics

\begin{tabular}{ccccc} 
Country & Age (M, SD) & Male (\%) & $\begin{array}{c}\text { Internet } \\
\text { penetration (\%) }\end{array}$ & Sample size \\
\hline Australia & $46.51(17.19)$ & 49.75 & 88.2 & 2004 \\
Czech Republic & $46.98(15.60)$ & 49.08 & 88.3 & 2003 \\
Germany & $48.75(15.54)$ & 50.05 & 89.6 & 2062 \\
Spain & $46.43(14.21)$ & 49.05 & 87.1 & 2006 \\
Finland & $47.83(16.47)$ & 48.88 & 92.5 & 2007 \\
France & $46.91(15.84)$ & 47.35 & 86.8 & 2000 \\
Ireland & $45.15(15.48)$ & 49.50 & 93.8 & 2002 \\
Italy & $47.93(14.83)$ & 48.53 & 86.7 & 2011 \\
Netherlands & $48.80(17.58)$ & 48.51 & 94.8 & 2006 \\
Poland & $45.71(15.26)$ & 48.29 & 73.3 & 2013 \\
UK & $48.30(15.84)$ & 44.41 & 94.8 & 2112 \\
USA & $48.61(17.09)$ & 44.60 & 89.9 & 2259
\end{tabular}

Note. Internet penetration figures are from Internet World Stats (http://internetworldstats.com). All other data from the 2017 Digital News Report (Newman et al. 2017)

\section{Questions}

All data used in the analysis that follows came from three survey questions. The first two are concerned with media use. Respondents were asked to specify which news outlets they used offline during the previous week. Then, they were asked which news outlets they used online (see Section 2 of the supplementary materials for the precise wording of the questions). Respondents selected from a list of around 30 of the most popular offline and online news outlets in each country, with a separate list for each. The main limitation was that it was not practical to ask about more than around 30 outlets in each country. This meant that most local and/or regional news outlets were not included in the survey. Furthermore, outlets with a weekly reach of $2 \%$ or less in the survey were excluded. As such, we are unable to consider outlets in the so-called 'long tail' of news media use. The long tail, and local news in 
particular, are undoubtedly important parts of the media environment, but, as we explain in more detail in the next section, because we effectively weight outlets by the size of their audience when producing the national-level news audience polarization scores, we believe that this omission ultimately has little impact upon our understanding of news audience polarization at the national level. The list of outlets included in the final analysis can be found in Tables 3-14 in the supplementary materials.

The third question captured data on individual political ideology. Respondents were asked to place themselves on a seven-point scale ranging from 'Very left-wing', through 'Centre', to 'Very right-wing', with a 'Don't know' option also available. Because we were aware that the left-right spectrum resonates more in some countries than in others, it was explained to respondents that "generally socialist parties would be considered 'left wing' whilst conservative parties would be considered 'right wing'". All right-leaning responses were coded 0.5 , left-leaning -0.5 , and centre responses coded 0 . Don't knows were removed from the analysis. We did not distinguish between different levels of left/right preference because we wanted to make the results more easily interpretable. Furthermore, because respondents in different countries tend to have different survey response styles, we did not want cultural preferences for more extreme responses to influence the results (Johnson et al. 2005). Recoding the measure in this way meant that respondents effectively made a threeway choice between left, right, and centre.

\section{Computations}

In order to eventually arrive at a single measure of news audience polarization in each country, we first computed the average (mean) political leaning of the entire sample in each country. Then, for every news outlet, we computed the average political leaning of their offline, online, and cross-platform audiences, and recorded the difference between these 
figures and the figure for the entire sample. For each outlet, this ultimately produced an audience political leaning score, with scores greater than zero denoting an audience that is more right-leaning than the population (and scores less than zero denoting a left-leaning audience). We have reason to believe that our scores are closely aligned with those from other studies, as a Pearson test shows a very strong correlation $(\mathrm{r}=.96, \mathrm{p}<.001)$ between our online news audience political leaning scores in the USA and those produced by Bakshy et al. (2015) using a similar procedure based on Facebook data (see Section 1 of the supplementary materials). Though we do not do so here, these scores (which are listed in full in Tables 3-14 in the supplementary materials) could potentially be used as proxies for the political slant of the outlet itself, as opposed to just the audience (e.g. Flaxman, Goel, and Rao 2016).

These measures can then be visualised (see Figure 1, top) for every outlet in a country to show the political leaning of their audience (the distance of each bubble from the midpoint, which represents the average political leaning of the sample) and the outlet's weekly reach (bubble size). ${ }^{2}$ As well as providing an intuitive picture of the level of news audience polarization in particular countries, these visualizations can help us explain how we measure polarization at the national level. The most polarized scenario we can imagine is one where the range of outlet scores is 1 . See Figure 1 (middle) for an example. Here, for illustrative purposes, half the population is left-leaning and half is right-leaning. The audience for outlet A is made up entirely of all the left-leaning people. Hence, the mean political leaning of its audience is -0.5 . Conversely, the audience for outlet B is made up entirely of right-leaning people, producing a score $0.5 .^{3} \mathrm{~A}$ simple measure of the level of polarization in this hypothetical media system is the (population) standard deviation. The most polarized system would have a score of 0.5 using this measure. The least polarized situation we can imagine is

\footnotetext{
${ }^{2}$ The news audience polarization visualizations contained in this paper were created using the ggplot 2 package for $\mathrm{R}$.

${ }^{3}$ In theory the audience political leaning score can be higher than 0.5 or lower than -0.5 , but the range cannot exceed 1 .
} 
shown in Figure 1 (bottom), because outlets A and B are used by the same proportion of leftleaning and right-leaning people, placing them both in the centre with a polarization score of 0 . This comparison also neatly highlights the difference between news audience polarization and audience fragmentation, because in both examples the audiences are completely fragmented (because they are non-overlapping), but the level of polarization is different.

Figure 1. Example polarization maps Example audience polarization

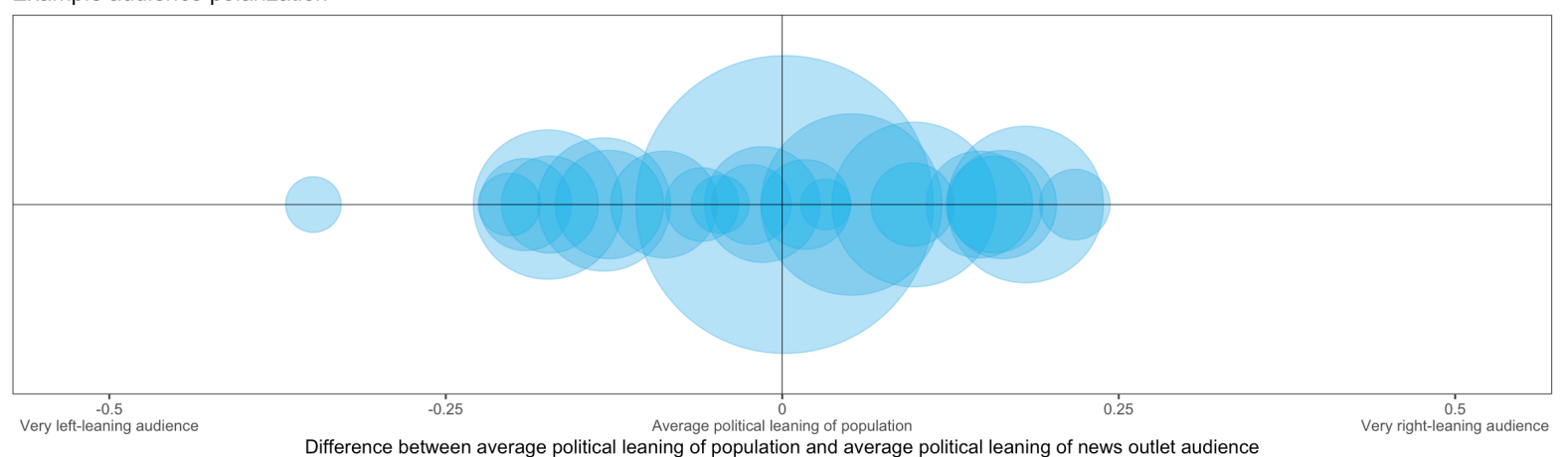

Maximum audience polarization

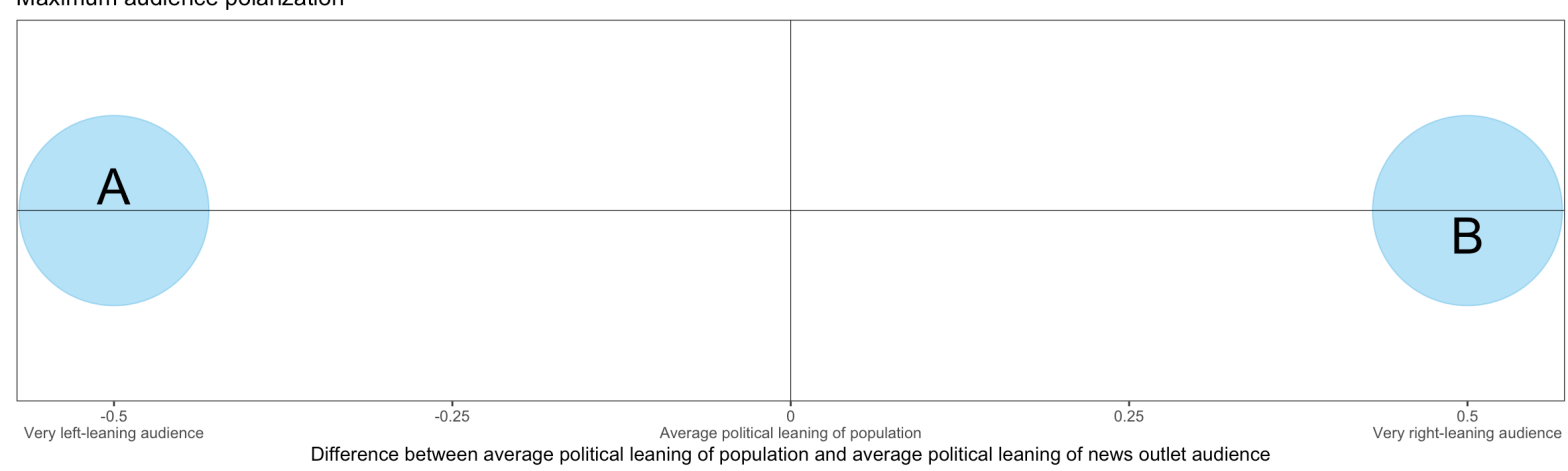

Minimum audience polarization

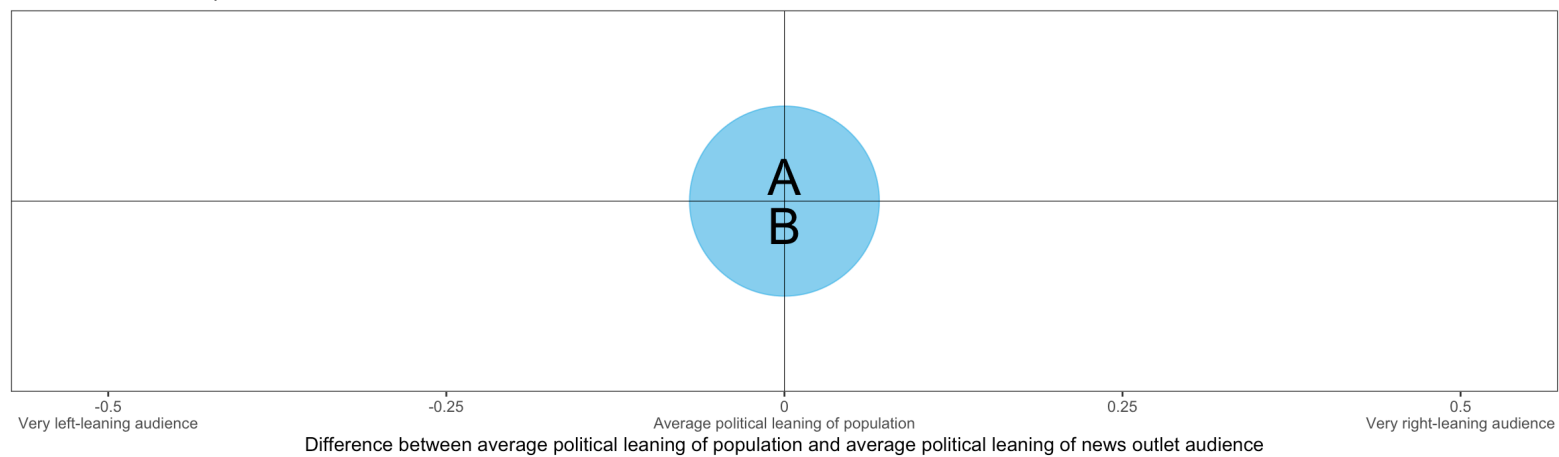

There is, however, a dimension we have not yet captured. It seems sensible to say that if we imagine two media systems with bubbles in exactly the same positions (i.e. the same 
audience political leaning scores), but one has larger outlets further from the centre, and the other has larger outlets closer to the centre, the former should be thought of as more polarized. Therefore, we account for this by computing the standard deviation of a list of values where the large outlets are effectively over-represented. More specifically, we take the standard deviation of a list of values where each outlet's audience political leaning score occurs as many times as it was used by respondents in the data. For example, an outlet that was used by 100 out of 2000 survey respondents will see its score included 100 times in the list, whereas an outlet used by 50 respondents will occur 50 times in the list. This ultimately means that the news audience polarization score will be more influenced by larger outlets.

As we have already seen, the maximum outlet range is 1 , so the maximum standard deviation is $0.5 .{ }^{4}$ Because we know what the maximum value is, we can also compute the extent to which the observed polarization reaches maximum polarization and express it as a percentage. These figures can then be compared across countries and platforms, and when new data is available, over time.

\section{Results}

Before addressing our hypotheses, we offer some descriptions based on the visualizations.

Let us first consider the cross-platform data for each country. The visualizations are presented in Figure 2. We can see straight away that each country shows a different pattern.

\footnotetext{
${ }^{4}$ If sample standard deviation is used instead, then the maximum can be greater than 0.5 . However, the use of the weighting system, and the subsequent increase in the number of values, means that the theoretical maximum is negligibly different from 0.5 , and it makes almost no difference whether the standard deviation is calculated using the population or sample formulas.
} 
Figure 2. Cross-platform news audience polarization maps

USA

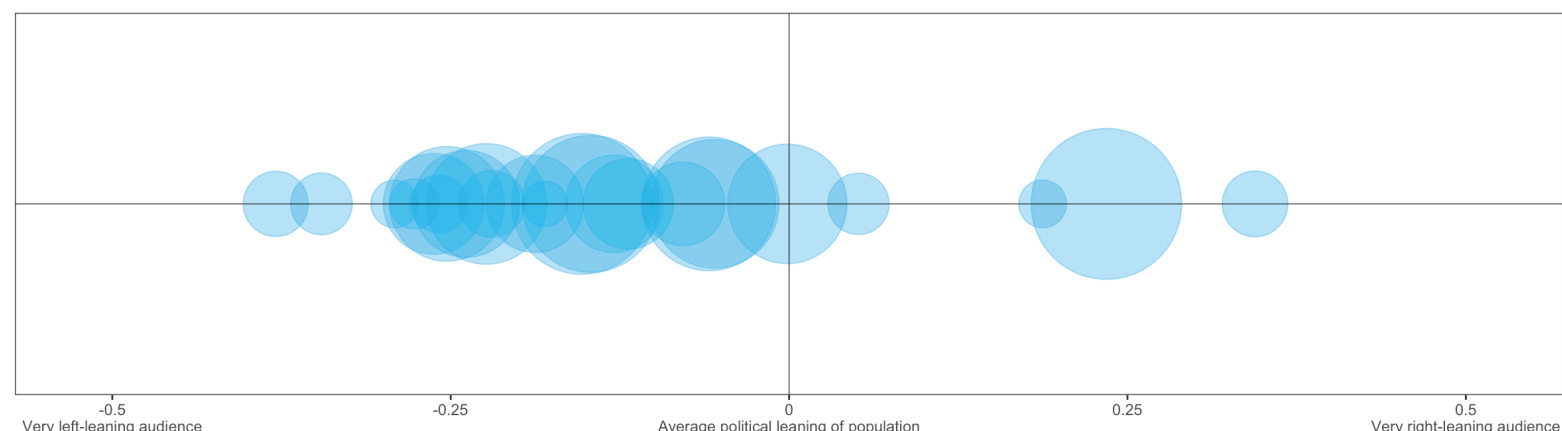

Difference between average political leaning of population and average political leaning of news outlet audience

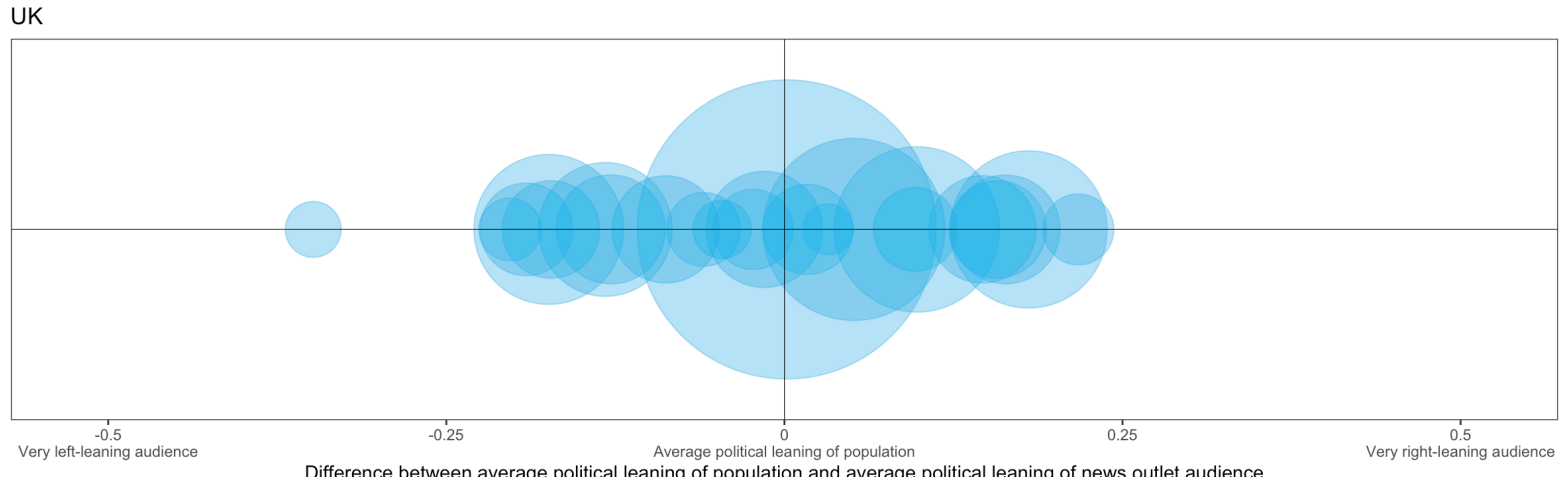

Difference between average political leaning of population and average political leaning of news outlet audience

France

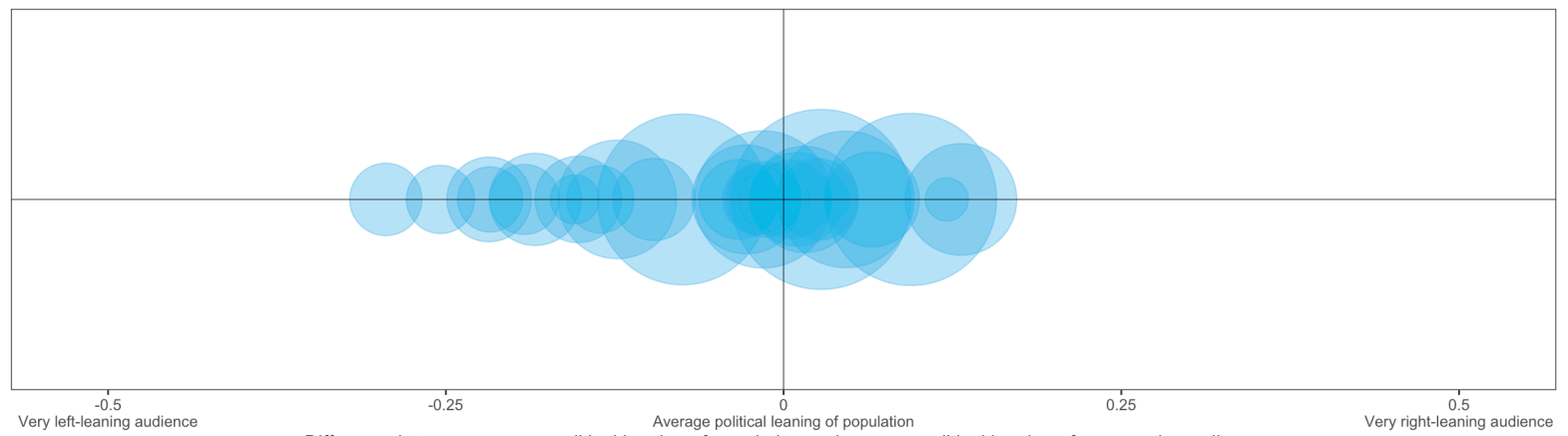

Difference between average political leaning of population and average political leaning of news outlet audience

Spain

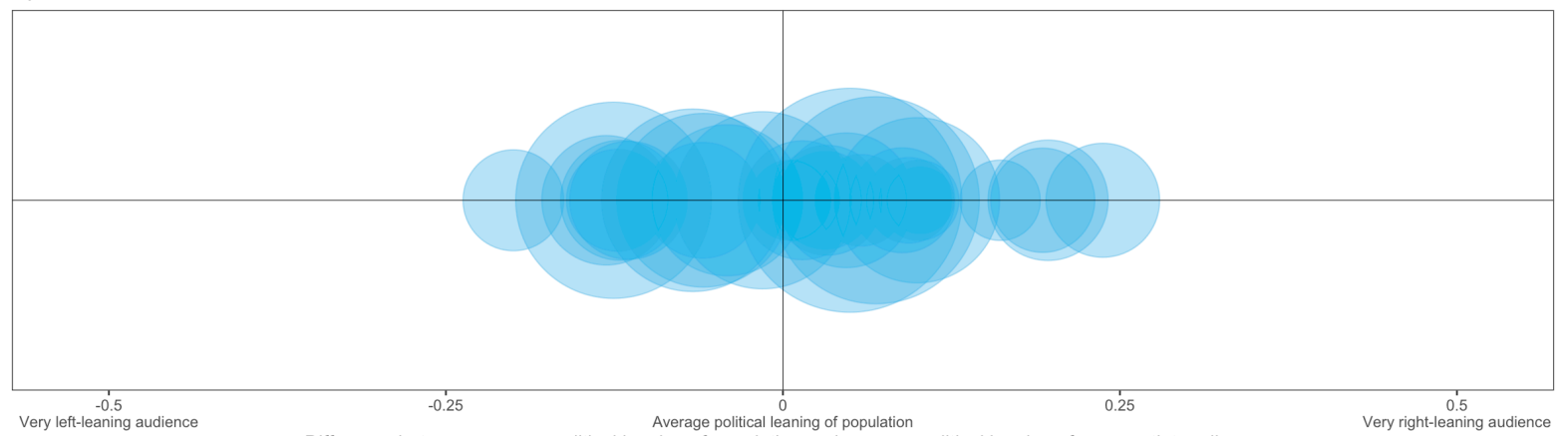

Difference between average political leaning of population and average political leaning of news outlet audience 


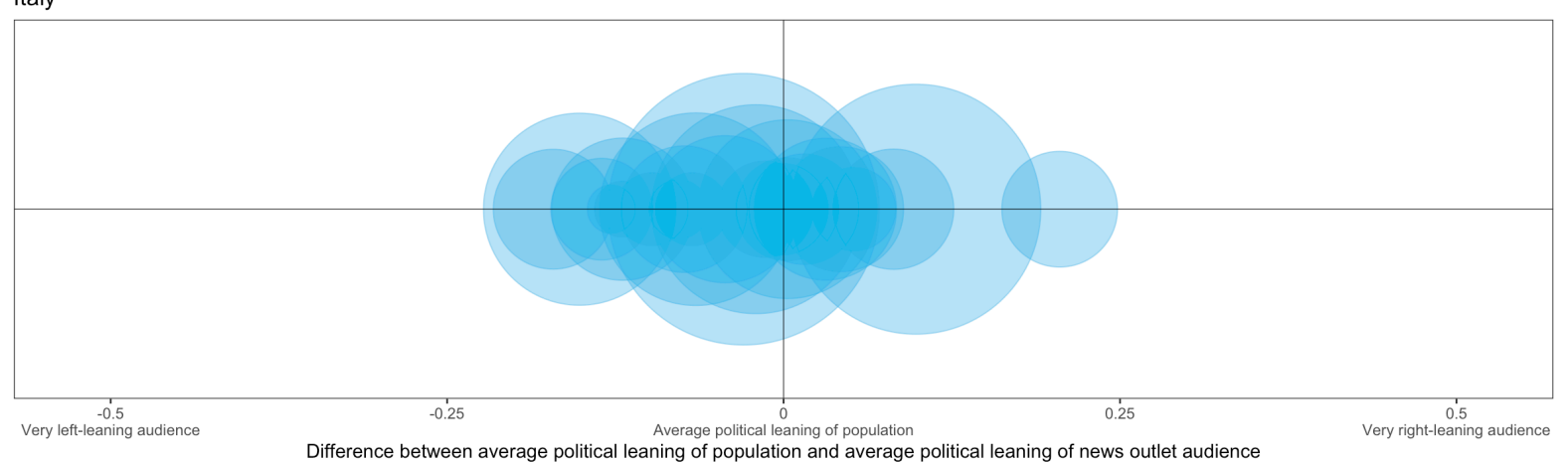

Poland

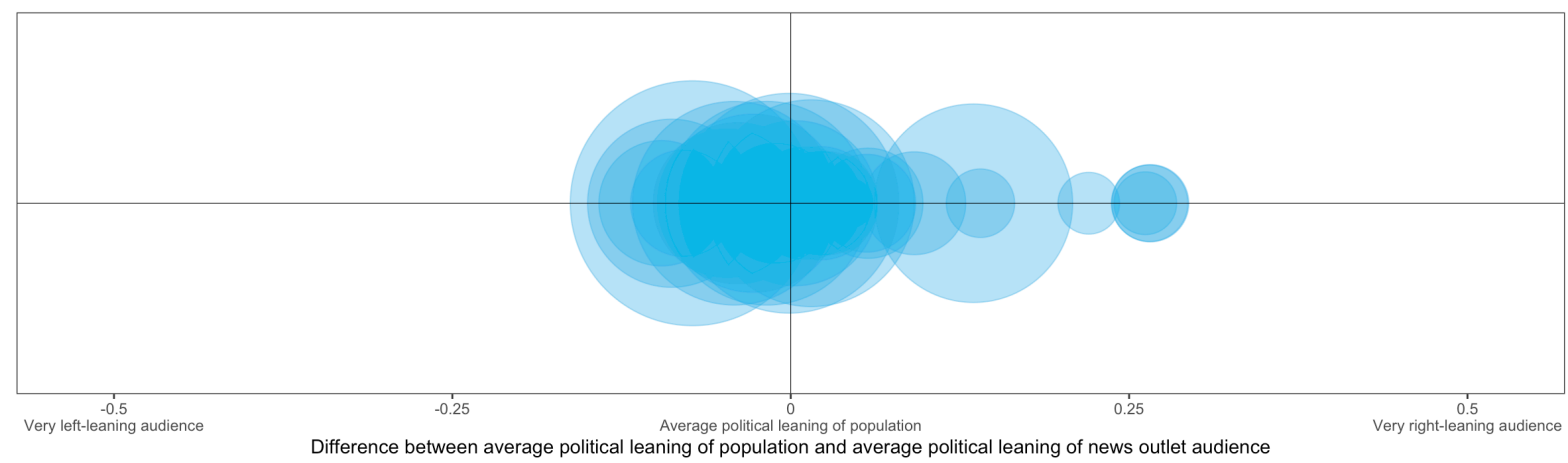

Australia

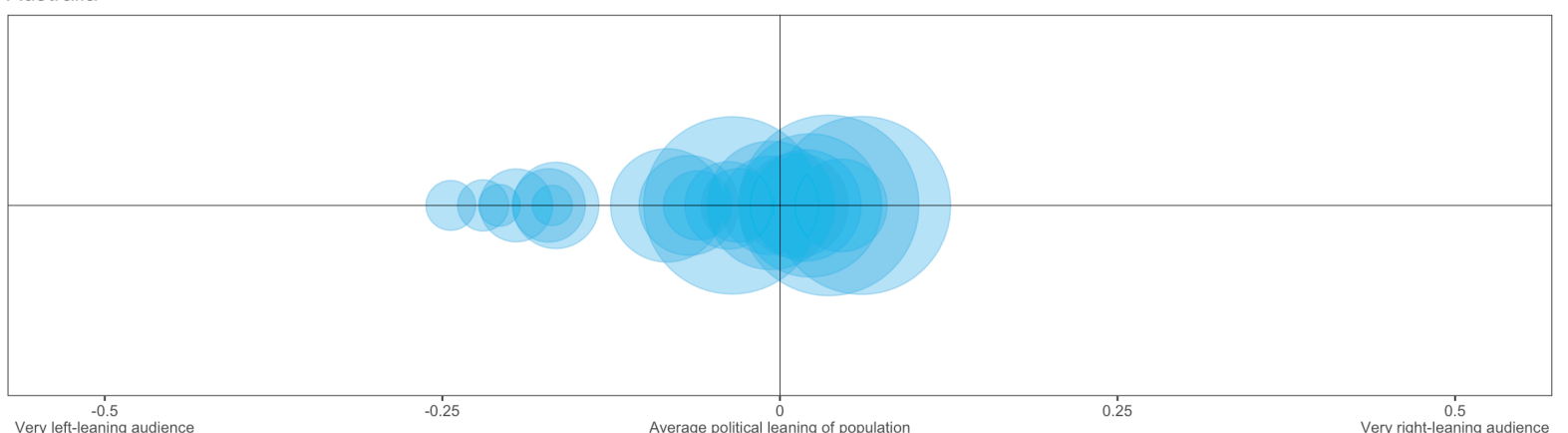

Difference between average political leaning of population and average political leaning of news outlet audience

Netherlands

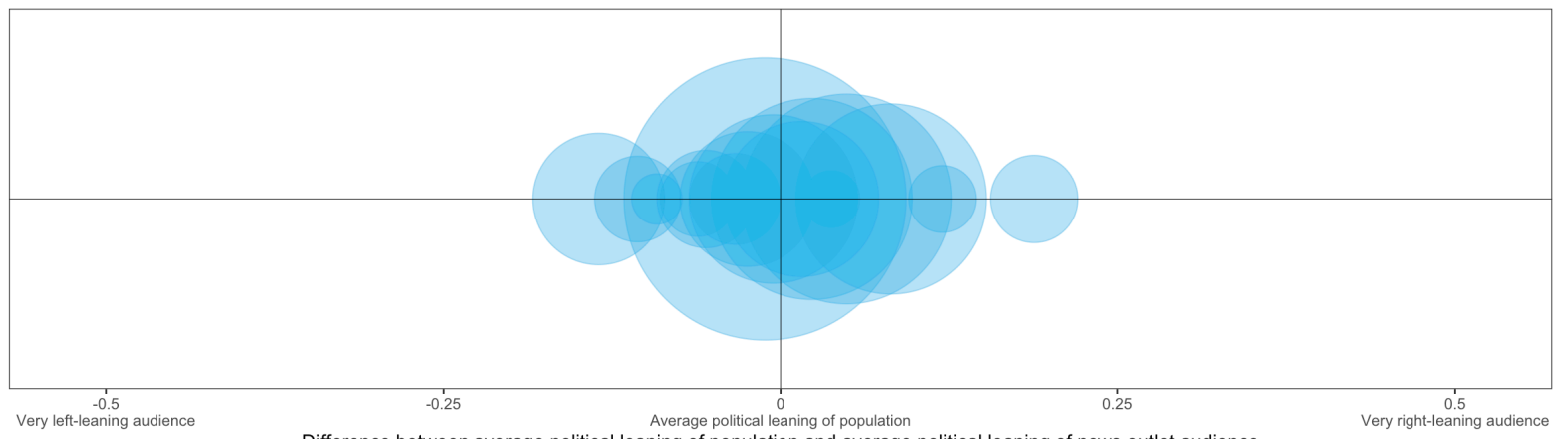

Difference between average political leaning of population and average political leaning of news outlet audience 


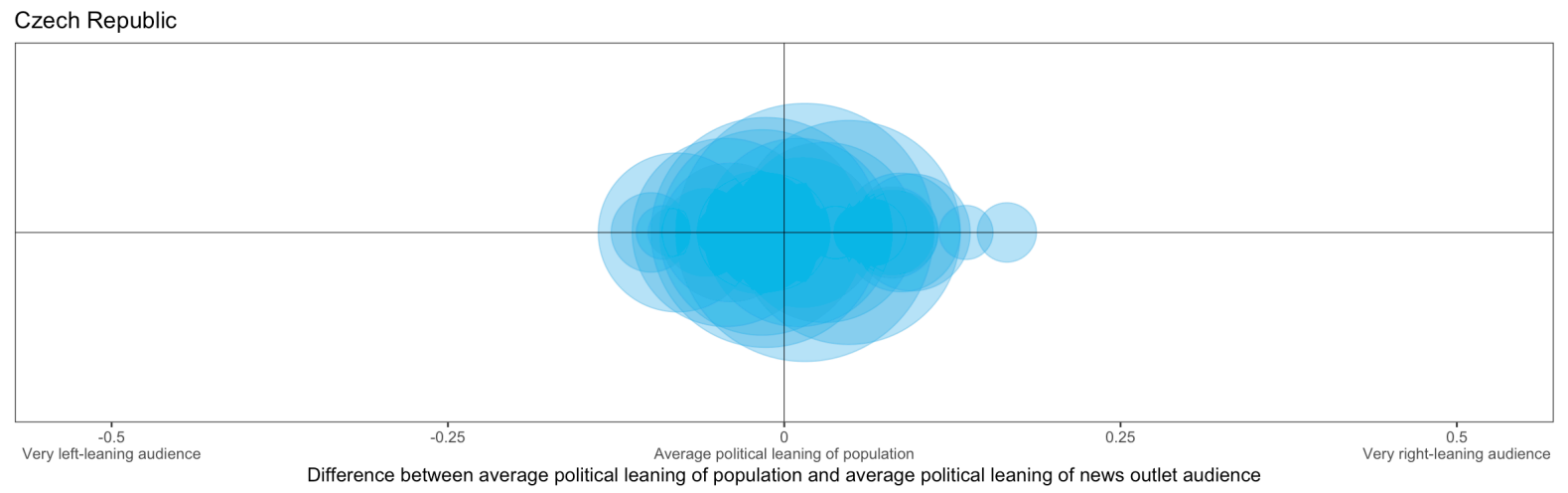

Finland

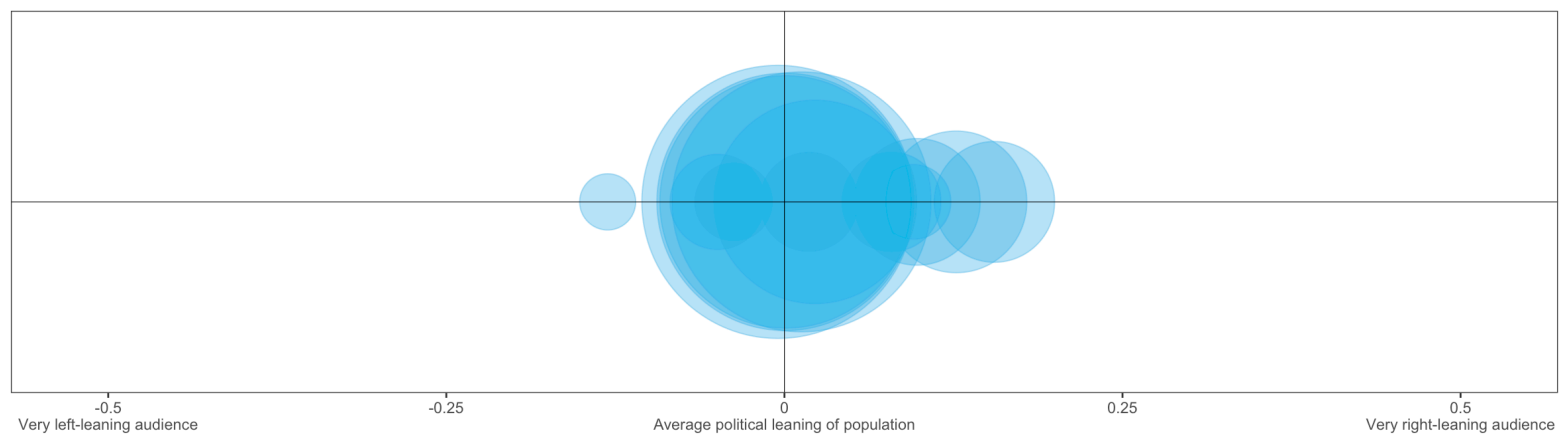

Difference between average political leaning of population and average political leaning of news outlet audience

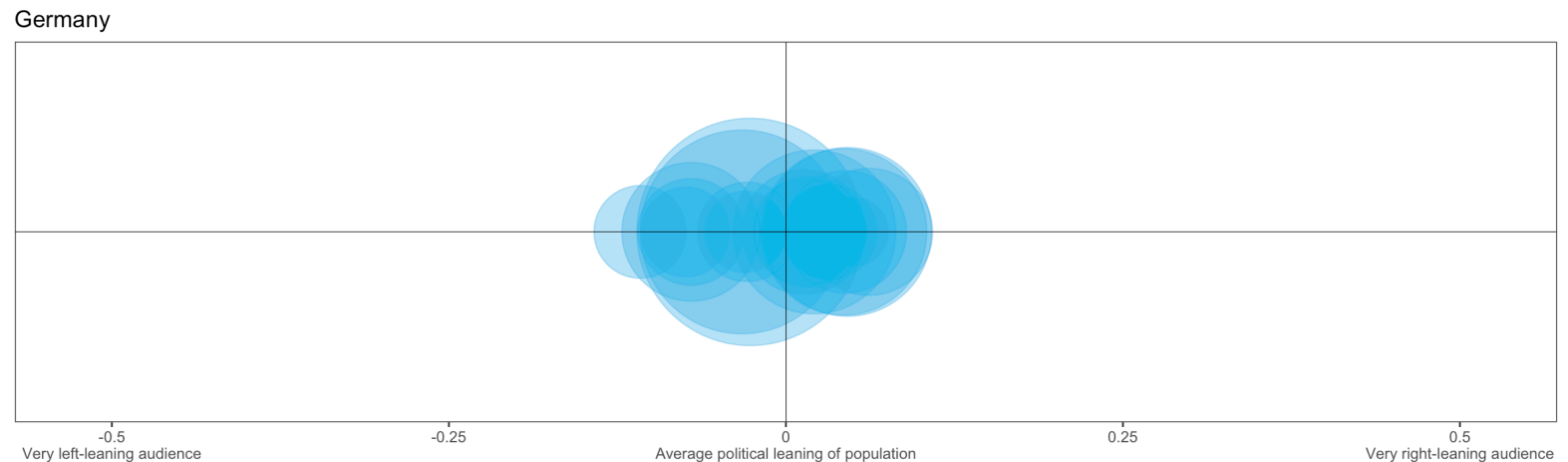

Difference between average political leaning of population and average political leaning of news outlet audience

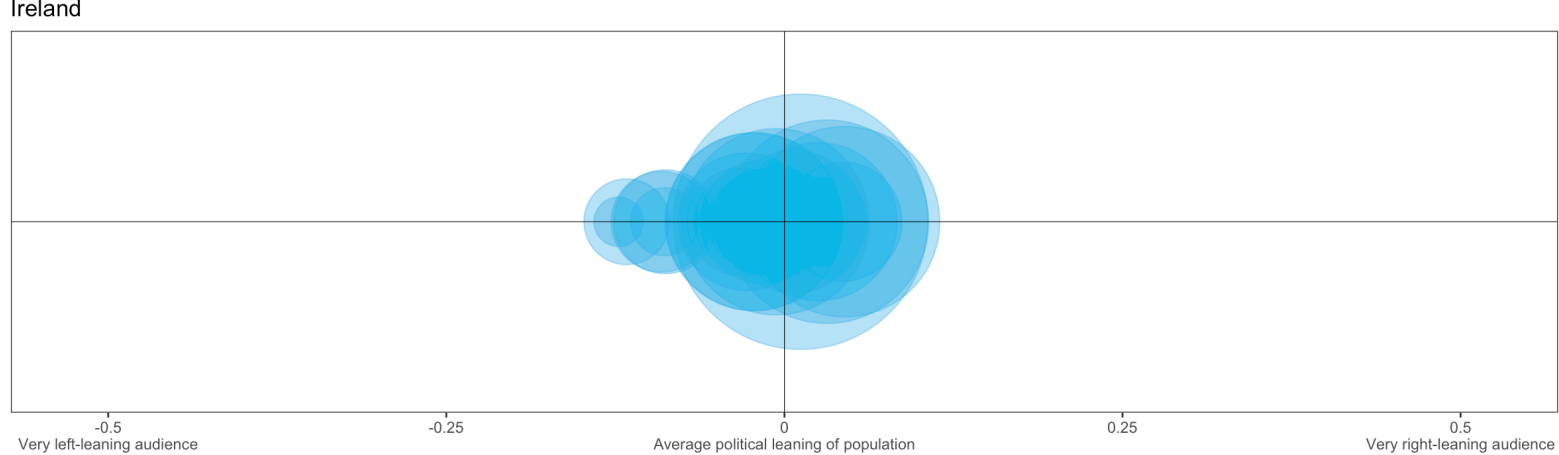

Difference between average political leaning of population and average political leaning of news outlet audience

The USA clearly looks to be the most polarized system, as the bubbles cover a

noticeably wider range than those in any other country, as well as there being relatively few 
outlets close to the centre. The outlet closest to the centre is Yahoo! News (audience political leaning score $=.00$, weekly reach $=24.68 \%$ ), which aggregates content from multiple sources (see Tables 3-14 in the supplementary materials for each outlet's audience political leaning score and weekly reach). One reason for this gap may be the absence of local news outlets, which would likely occupy the centre given they are focussed on serving a geographically-similar audience rather than an ideological group. Compared to some of the other countries - particularly those with democratic corporatist media systems - the outlets with the largest reach are actually quite small. Overall, the USA does not exhibit many commonalities with any of the other countries.

In the UK, outlets are also relatively spread out, with popular newspapers such as the Guardian (-.17, 19.65\%) and the Daily Mail (.18, 21.64\%) exhibiting quite prominent leftand right-leaning audiences, respectively. The Canary $(-.35,2.65 \%)$, a pro-Corbyn ${ }^{5}$ digitalborn news site, has a small but particularly left-wing audience. But the most striking difference between the UK and the USA is the presence of public broadcaster the BBC (.00, 77.88\%) and its very large, central bubble, indicating a sizeable, politically diverse audience. It is noticeable, however, that aside from the $\mathrm{BBC}$, the centre of the map is less crowded than in many other countries, indicating that most outlets in the UK have skewed audiences, thus raising the overall degree of polarization. The same is true in Australia, but to a lesser extent. Here, public broadcaster $\mathrm{ABC}(-.04,45.76 \%)$ is one of the three most popular outlets, and is relatively close to the centre of the map. However, other outlets - whether on the left or the right - have audiences that are less skewed than those in the UK or the US. This is even more true in Ireland, where there is a large, concentrated block of outlets in the centre, including the largest of them all, public broadcaster RTÉ $(.01,67.18 \%)$.

\footnotetext{
${ }^{5}$ At the time of writing Jeremy Corbyn is the leader of the UK's Labour Party.
} 
A similar pattern is evident in Finland, Germany, and the Netherlands, all of which also have widely-used public service media. All three are considered part of the democratic corporatist model, characterised by declining levels of political parallelism and low levels of media-party parallelism. Our data on news audience polarization is somewhat aligned with this, as the bubbles - whether they represent newspapers, broadcasters, or digital-born sitesare typically clustered around the centre.

If we compare these to the polarized pluralist/southern countries - namely Italy, France and Spain — we see outlets with more skewed audiences. In contrast to most other countries, where audiences are in a sense distributed normally—with larger outlets closer to the centre of the map — the larger outlets here are just as likely to clearly have a left or a right skew. Indeed, all three countries have at least one outlet with a large left-leaning, a large right-leaning, and a large centrist audience.

Poland and the Czech Republic display quite different patterns of news audience polarization. The Czech Republic appears most similar to the democratic corporatist countries because it has large, central outlets, and the most popular of the them all is public broadcaster $\check{C} \mathrm{~T}(.02,68.30 \%)$. Poland has more skewed news audiences, giving the map a similar shape to the polarized pluralist countries. What both countries have in common is that they are home to very large web portals that also carry news: Seznam $(-.01,54.12 \%)$ in the Czech Republic, and Onet.pl (.00, 51.86\%), WP.pl (.02, 45.90\%) and Interia (.00, 29.16\%) in Poland. These sites still attract large audiences and often aggregate news from a range of other sources, meaning that they are positioned near the centre of the charts, reducing crossplatform news audience polarization. 
Figure 3. Percentage of theoretical maximum cross-platform news audience polarization

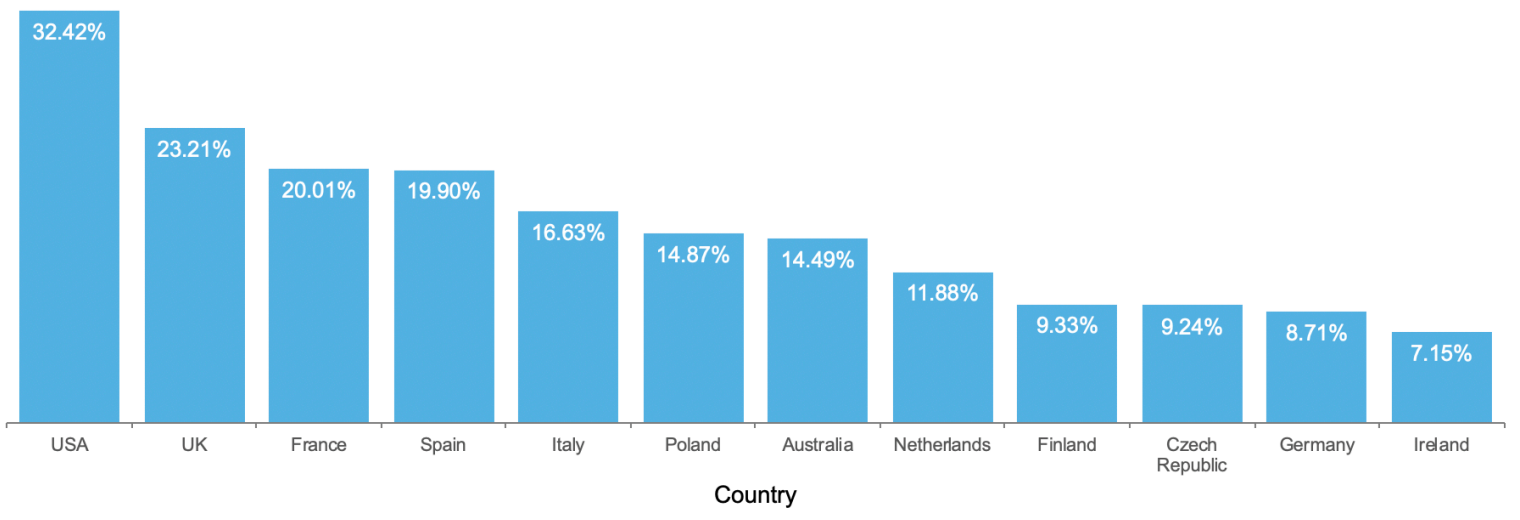

The differences we see in Figure 2 are reflected in the cross-platform news audience polarization scores in Figure 3. The cross-platform figures are also broadly in line with the expectations stated in H1. Countries with democratic corporatist media systems-like Finland (9.33\%), Germany (8.71\%) and the Netherlands (11.88\%) - have roughly half the level of news audience polarization than the polarized pluralist/southern countries-France (20.01\%), Spain (19.90\%), and Italy (16.63\%). We thus find support for H1, as the level of polarization is always higher in countries with polarized pluralist/southern media systems than in countries with democratic corporatist media systems.

The USA (32.42\%) has by far the highest cross-platform news audience polarization, with the observed polarization around one third of the theoretical maximum. The USA is followed by the UK (23.21\%), which has news audience polarization at about one quarter of the maximum. Ireland differs strikingly from the other members of the liberal model in that it has the lowest polarization score of all $(7.15 \%)$, but this is in line with previous studies which have also found it to have particularly low levels of media-party parallelism (van Kempen 2007). Therefore, our answer to RQ1 is that countries with liberal media systems exhibit highly inconsistent levels of cross-platform news audience polarization. Poland (14.97\%), Australia (14.49\%) and the Czech Republic (9.24\%) show relatively moderate levels of news audience polarization. 
We now turn to RQ2, and within-country differences between offline and online news audiences. The visualizations for offline and online polarization in each country are included in Section 3 of the supplementary materials. In terms of how spread-out the bubbles are, the online and offline maps in most countries appear quite similar. But there are also subtle differences. In the UK, for example, on the offline map the outlets with right-leaning audiences are larger, but online the outlets with left-leaning audiences are larger. This reflects the fact that the printed press is primarily made up of outlets with a right-leaning editorial line, such as the Times $(.16,5.87 \%)$ and the Telegraph $(.15,4.36 \%)$. But online, these outlets operate paywalls, whereas the larger left-leaning outlets like the Guardian $(-.17,17.90 \%)$ and the Mirror $(-.12,4.78 \%)$ are free. In Germany and France, the online and offline maps look very different from one another. This is chiefly due to differences in overall news audience size. In most countries, it is clear that the offline reach of the most popular outlets is larger than the online reach. In Germany, where only around $65 \%$ of the population regularly consume news online (Newman et al. 2018), the difference is particularly noticeable.

Figure 4 contains the polarization scores for offline and online news audiences in each country. In eight of the 12 countries, online news audience polarization is higher than offline news audience polarization. Offline polarization was higher in Poland, Czech Republic, Finland, and Italy. The biggest gap is in Australia, but in Spain, Italy, and Finland the difference is very small. As such, our answer to RQ2 is that online news audiences do appear to be slightly more polarized in most cases, but in general the differences are small. Perhaps the most noticeable feature of Figure 4 is that the differences between online and offline are small, and it retains the same basic shape as the cross-platform chart in Figure 2. In other words, the themes identified by the comparative tradition can explain many of the patterns we see, regardless of the platform. 
Figure 4. Percentage of theoretical maximum offline and online news audience polarization

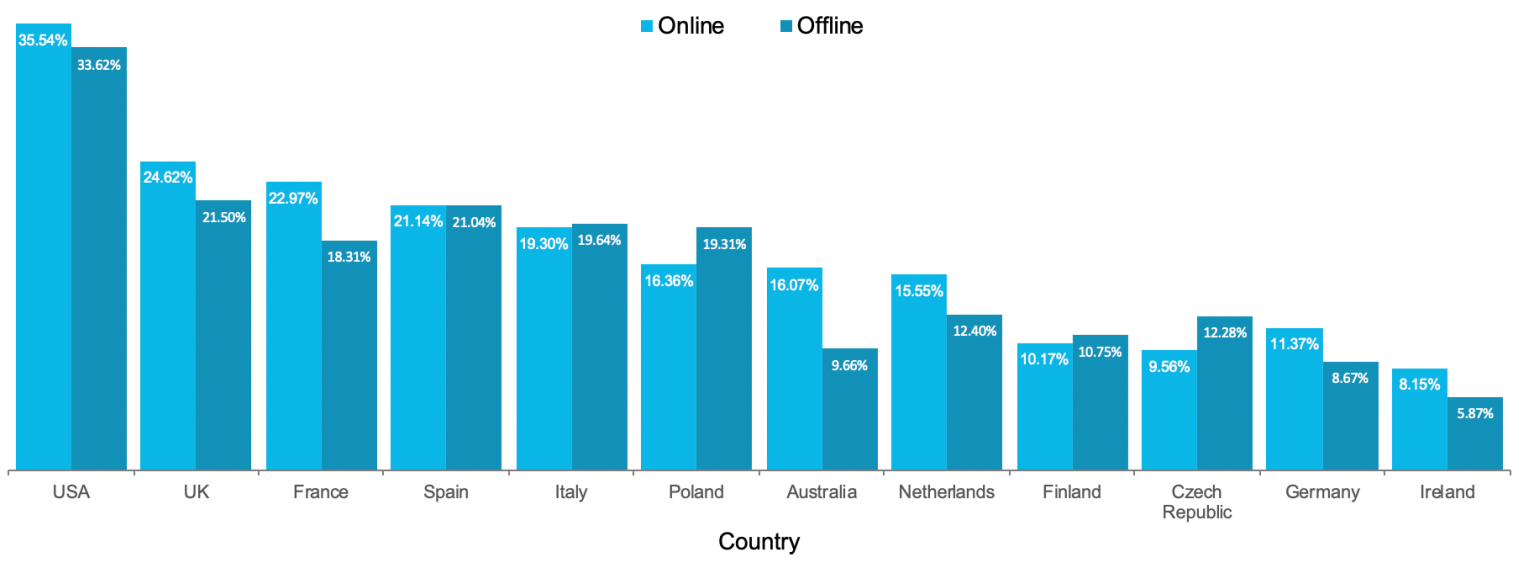

\section{Limitations}

Before moving to a discussion of the results, we first outline some limitations that should be kept in mind. The first relates to the use of a survey to measure media use. The reliance on recall ultimately means that the data may not always provide a completely accurate picture of people's news consumption (Prior 2009). There is also evidence to suggest that people are better at correctly remembering news stories when they access them directly as opposed to arriving at them via search engines or social media (Kalogeropoulos, Fletcher, and Nielsen 2019). Given that the level of reliance on these forms of 'distributed' news use varies across countries (Newman et al. 2018), we might also expect recall error to vary. There are also some limitations associated with the use of this particular dataset. As the data come from an online panel, respondents were not selected entirely at random. The results will also underrepresent the media habits of those who are not online. Those under-represented are typically older, less affluent, and have lower levels of formal education. In countries where internet penetration is very high this may not present a problem, but it is particularly important to keep in mind for countries where internet penetration is relatively low (see Table 2).

Turning to the measures used, there are limitations associated with simply asking respondents to select from a list which news outlets they used in the last week. Some research 
has shown that open-ended responses provide a more accurate measure of media exposure (Guess 2015), but these are impractical for large-scale multi-country surveys. Other studies have emphasised that media attention is a better predictor of media effects than media exposure. For example, the 'list-frequency technique' has been found to produce measures that are better able to predict current affairs knowledge than the 'list-technique' used in this study (Andersen, de Vreese, and Albæk 2016). Although it would probably be possible to media attention measures to arrive at more accurate levels of news audience polarization, this has not yet been shown, and we leave it for future research to investigate.

We also acknowledge that asking people to place themselves on a left-right scale is potentially problematic. Left-right labels are likely to mean different things in different countries, and people's self-placement is likely to reflect group identities as well as issue preferences. However, despite these shortcomings, recent research has shown that left-right attitudes are still more important than populist attitudes when it comes to news selection in Western Europe (Pew 2018), and more generally "left-right self-placement is the best singlequestion indicator of mass ideology" (Caughey, O’Grady, and Warshaw 2019).

\section{Discussion}

News audience polarization is often seen as a problematic development, able to undermine the kind of shared public space that democracies need. How polarized news audiences in fact are, how this differs across countries, and whether news audiences are more polarized online or offline, are therefore crucially important questions. In this paper, we have approached them by developing an audience-centric measure of news audience polarization, using it to compare, first, across 12 countries with different media systems and, second, across offline and online media. We therefore respond to calls for more focus on audiences in comparative media research (Blumler and Gurevitch 1995) and for more work acknowledging that 
audiences consume media across platforms, and that it is therefore potentially misleading to treat print, broadcast, or online in isolation (Fletcher and Nielsen 2017).

We found, first, that countries with polarized pluralist/southern media systems have higher levels of news audience polarization than democratic corporatist countries. This suggests that the systemic factors identified by the comparative tradition are potentially useful for our understanding of polarization. However, we also found that countries originally grouped within the liberal model now present less consistent patterns than traditionally thought. The USA is far more polarized than any other country covered here, with the UK in second, and Ireland last. However, it is also important to recognise that neither the UK (23.21\%) nor the US (32.42\%) displayed particularly high levels of news audience polarization, at least when compared to a theoretical maximum $(100 \%)$ where all left-leaning people use one set of news sources, and all right-leaning people use a different, nonoverlapping set. Such a situation is unlikely to ever occur in practice, but it highlights that many people may be overestimating the extent of polarized news consumption patterns, perhaps similar to how many seem to have overestimated the extent of algorithmic filter bubbles and echo chambers.

For the most part, insights from comparative media research do seem to help explain some of the patterns we see when we look at news audience polarization. However, it is important to keep in mind that the categories developed by comparative media researchers are based on many other dimensions that have little to do with audience behaviour, so we should not expect these categories to act as a perfect guide. But, our findings could suggest that some of the traditional concepts used in comparative media research need to be revised, as others have also argued (Brüggemann et al. 2014; Hallin and Mancini 2016; Nechushtai 2018). The idea that liberal countries exhibit low levels of political parallelism seems increasingly at odds with empirical data, something that is highlighted by our own results for 
news audience polarization. Similarly, grouping the USA and the UK together with Ireland, at least when it comes to news audience behaviour, looks increasingly problematic.

We found, second, that although some countries do indeed have more polarized news audiences online, the picture is mixed, as other countries present the opposite trend, and the differences between online and offline are small in most cases. The results do not indicate whether news audiences are becoming more polarized over time as more and more people get their news online. However, because current differences between online and offline polarization are small, we should be cautious about assuming that overall patterns of news use will be rapidly transformed by digital access.

News audience polarization as a process in playing out differently in different countries. This raises an important question, namely, what is causing these differences? We will leave this question for future research, but we believe that any answer should draw on what we already know about inherited historical and structural factors, as well as longstanding differences in political culture and market structure. One possibility is that strong public service broadcasters reduce cross-platform news audience polarization, because they are sometimes required to provide impartial coverage — and perhaps as a result — they often have very large broadcast news audiences. Comparative media research has repeatedly emphasised the importance of public service media, and has usually associated strong public broadcasting with democratic corporatism. This could be one of the reasons why democratic corporatist countries tend to have lower levels of news audience polarization. Using our measure, any outlet that is able to attract a large audience from across the political spectrum will lower the cross-platform news audience polarization score. But many of the countries with the lowest scores, such as Germany, Finland, Ireland, the Czech Republic, and the Netherlands, are also those where the most popular news outlet is the public broadcaster. The clear exception is the $\mathrm{UK}$, where the BBC is relatively well-funded, required to be impartial, 
and has very large cross-platform reach. Here, news audience polarization is high due to the partisan make-up of audiences for newspaper outlets. Again, this is consistent with comparative research that sees the UK as a hybrid case thanks to the combination of strong public service media and a highly partisan press. It's not clear what patterns we would see if the BBC did not exist, but it is entirely possible that people would instead self-select news outlets most closely aligned with their political views, thus raising the level of news audience polarization even further.

Figure 5. Difference in offline and online polarization plotted against the use of distributed news (social media, search, or aggregators)

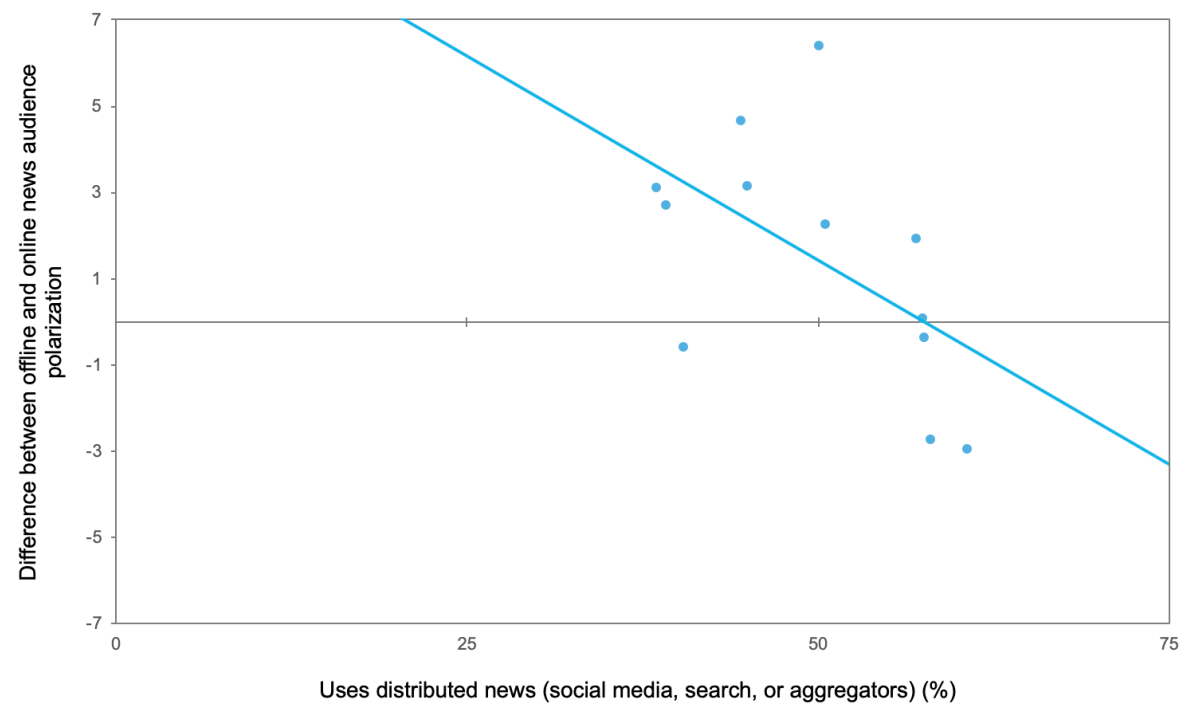

We would also like to suggest that cross-country differences in the use of distributed news (access via search engines, social media, and news aggregators) and web portals could be a factor. We do not have enough data points to formally test possible country-level explanations, but we offer one observation. If we plot the gap between online and offline polarization against the proportion of people within a country that used some form of 
distributed news during the same week (see Figure 5), we see that as the use of distributed news rises, the gap between online and offline polarization falls $(r=-.54){ }^{6}$

Poland and the Czech Republic, which have the highest level of distributed news use, also have lower news audience polarization online. Distributed news might therefore have a moderating effect. We should, however, be very cautious in interpreting the results in this way, especially with so few data points. The relative popularity of distributed news could be important, but it will not be the only relevant factor. Because Poland and the Czech Republic are home to very popular web portals, such as Seznam, Onet.pl and WP.pl, that aggregate news from mainstream outlets, we expect them to attract diverse audiences, thus lowering online news audience polarization. But elsewhere, high levels of social media use may expose people to less mainstream, more partisan news sites, creating the opposite effect.

Finally, we believe that this paper makes two additional contributions we hope future research will build on. First, the audience-centric approach to measuring news audience polarization developed here is useful beyond the study of left-right polarization. While leftright preferences are certainly one important driver of audience behaviour, they are not the only factor relevant for understanding the dynamics of public debate. Our approach permits the analysis of audience polarization in terms of other political attitudes, including populist beliefs, as well as other variables, for example, age, interest in news, or income and education. Particularly in Europe, these factors may be more important than politics in understanding the dynamics of audience attention (Castro-Herrero, Nir, and Skovsgaard 2018). Second, the empirical findings presented here challenge conventional wisdom (largely based on work from the USA) about how polarized audiences are, and how online audiences

\footnotetext{
${ }^{6}$ Figures for distributed news were produced by asking respondents in each country whether they had done one or more of the following in the last week: (i) used a search engine (e.g. Google, Bing) and typed in a keyword about a particular news story, (ii) used a newsreader site or app that aggregates news links (e.g. Flipboard, Apple News, SmartNews), and (iii) used social media and came across news that way (e.g. Facebook, Twitter, LinkedIn). Descriptive statistics can be found in Table 2 in the Supplementary Materials.
} 
differ from offline audiences. Our study shows that the USA is very much an outlier with respect to news audience polarization. This chimes with other studies that have found that the US media system often exhibits unique characteristics, such as a long-term decline in press trust, that are largely absent elsewhere (Hanitzsch, van Dalen, and Steindl 2017). This is a powerful reminder of the importance of comparative research and the dangers of naïve universalism based on single-country case studies. We should always keep this in mind when trying to generalize based on studies from the USA.

\section{Funding}

This research was supported by Google UK as part of the Google News Initiative.

\section{References}

Andersen, Kim, Claes H. de Vreese, and Erik Albæk. 2016. 'Measuring Media Diet in a High-Choice Environment - Testing the List-Frequency Technique'. Communication Methods and Measures 10 (2-3): 81-98.

Arceneaux, Kevin, Martin Johnson, and John Cryderman. 2013. 'Communication, Persuasion, and the Conditioning Value of Selective Exposure: Like Minds May Unite and Divide but They Mostly Tune Out'. Political Communication 30 (2): 21331.

Bakshy, Eytan, Solomon Messing, and Lada A. Adamic. 2015. 'Exposure to Ideologically Diverse News and Opinion on Facebook'. Science 348: 1130-32.

Blumler, Jay G., and Michael Gurevitch. 1995. The Crisis of Public Communication. London: Routledge. 
Brüggemann, Michael, Sven Engesser, Florin Büchel, and Edda Humprecht. 2014. 'Hallin and Mancini Revisited: Four Empirical Types of Western Media Systems'. Journal of Communication 64 (6): 1037-65.

Castro-Herrero, Laia, Lilach Nir, and Morten Skovsgaard. 2018. 'Bridging Gaps in CrossCutting Media Exposure: The Role of Public Service Broadcasting'. Political Communication 35 (4): 542-65.

Caughey, Devin, Tom O’Grady, and Christopher Warshaw. 2019. 'Political Ideology in European Mass Publics, 1981-2016'. American Political Science Review 0 (0): 1-20.

Dubois, Elizabeth, and Grant Blank. 2018. 'The Echo Chamber Is Overstated: The Moderating Effect of Political Interest and Diverse Media'. Information, Communication \& Society 21 (5): 729-45.

Esser, Frank, and Andrea Umbricht. 2013. 'Competing Models of Journalism? Political Affairs Coverage in US, British, German, Swiss, French and Italian Newspapers'. Journalism 14 (8): 989-1007.

Flaxman, Seth, Sharad Goel, and Justin M. Rao. 2016. 'Filter Bubbles, Echo Chambers, and Online News Consumption'. Public Opinion Quarterly 80: 298-320.

Fletcher, Richard, and Rasmus Kleis Nielsen. 2017. 'Are News Audiences Increasingly Fragmented? A Cross-National Comparative Analysis of Cross-Platform News Audience Fragmentation and Duplication'. Journal of Communication 67 (4): 47698.

_ 2018. 'Are People Incidentally Exposed to News on Social Media? A Comparative Analysis'. New Media \& Society 20 (7): 2450-68.

Garrett, R. Kelly, Shira Dvir Gvirsman, Benjamin K. Johnson, Yariv Tsfati, Rachel Neo, and Aysenur Dal. 2014. 'Implications of Pro- and Counterattitudinal Information 
Exposure for Affective Polarization'. Human Communication Research 40 (3): 30932.

Guess, Andrew M. 2015. 'Measure for Measure: An Experimental Test of Online Political Media Exposure'. Political Analysis 23 (1): 59-75.

Hallin, Daniel C., and Paolo Mancini. 2004. Comparing Media Systems: Three Models of Media and Politics. Cambridge: Cambridge University Press.

—. 2013. “"Comparing Media Systems” between Eastern and Western Europe'. In Media Transformations in the Post-Communist World: Eastern Europe's Tortured Path to Change, edited by Peter Gross and Karol Jakubowicz, 15-32. Lanham: Lexington Books.

_. 2016. 'Ten Years After Comparing Media Systems: What Have We Learned?' Political Communication 34 (2): 155-71.

Hanitzsch, Thomas, Arjen van Dalen, and Nina Steindl. 2017. 'Caught in the Nexus: A Comparative and Longitudinal Analysis of Public Trust in the Press'. International Journal of Press/Politics 23 (1): 3-23.

Hetherington, Marc J. 2009. 'Review Article: Putting Polarization in Perspective'. British Journal of Political Science 39: 413-48.

Iyengar, Shanto, and Kyu S. Hahn. 2009. 'Red Media, Blue Media: Evidence of Ideological Selectivity in Media Use'. Journal of Communication 59 (1): 19-39.

Johnson, Timothy, Patrick Kulesa, Young Ik Cho, and Sharon Shavitt. 2005. 'The Relation Between Culture and Response Styles: Evidence from 19 Countries'. Journal of Cross-Cultural Psychology 36 (2): 264-77.

Kalogeropoulos, Antonis, Richard Fletcher, and Rasmus Kleis Nielsen. 2019. 'News Brand Attribution in Distributed Environments: Do People Know Where They Get Their News?' New Media \& Society 21 (3): 583-601. 
Kempen, Hetty van. 2007. 'Media-Party Parallelism and Its Effects: A Cross-National Comparative Study'. Political Communication 24 (3): 303-20.

Kobayashi, Tetsuro, and Kazunori Inamasu. 2015. 'The Knowledge Leveling Effect of Portal Sites'. Communication Research 42: 482-502.

Lelkes, Yphtach. 2016. 'Mass Polarization: Manifestations and Measurements'. Public Opinion Quarterly 80: 392-410.

Levendusky, Matthew. 2013. How Partisan Media Polarize America. Chicago: University of Chicago Press.

Nechushtai, Efrat. 2018. 'From Liberal to Polarized Liberal? Contemporary U.S. News in Hallin and Mancini’s Typology of News Systems'. International Journal of Press/Politics 23 (2): 183-201.

Nelson, Jacob L., and James G. Webster. 2017. 'The Myth of Partisan Selective Exposure: A Portrait of the Online Political News Audience'. Social Media + Society 3 (3): 1-13. Newman, Nic, Richard Fletcher, Antonis Kalogeropoulos, David A. L. Levy, and Rasmus Kleis Nielsen. 2017. 'Reuters Institute Digital News Report 2017'. Oxford: Reuters Institute for the Study of Journalism.

—. 2018. 'Reuters Institute Digital News Report 2018'. Oxford: Reuters Institute for the Study of Journalism.

Pariser, Eli. 2011. Filter Bubbles: What the Internet Is Hiding from You. London: Penguin. Pew. 2014. 'Political Polarization in the American Public: How Increasing Ideological Uniformity and Partisan Antipathy Affect Politics, Compromise and Everyday Life'. Washington D.C.: Pew Research Centre.

—. 2018. 'In Western Europe, Public Attitudes Toward News Media More Divided by Populist Views Than Left-Right Ideology'. Washington D.C.: Pew Research Centre. 
Prior, Markus. 2005. 'News vs. Entertainment: How Increasing Media Choice Widens Gaps in Political Knowledge and Turnout'. American Journal of Political Science 49: 57792.

_ 2009. 'The Immensely Inflated News Audience: Assessing Bias in Self-Reported News Exposure'. Public Opinion Quarterly 73: 130-43.

- 2013. 'Media and Political Polarization'. Annual Review of Political Science 16: $101-27$.

Skovsgaard, Morten, Adam Shehata, and Jesper Strömbäck. 2016. 'Opportunity Structures for Selective Exposure: Investigating Selective Exposure and Learning in Swedish Election Campaigns Using Panel Survey Data'. International Journal of Press/Politics 21 (4): 527-46.

Stroud, Natalie Jomini. 2011. Niche News: The Politics of News Choice. Oxford: Oxford University Press.

Sunstein, Cass R. 2017. \#republic: Divided Democracy in the Age of Social Media. Princeton: Princeton University Press.

Trilling, Damian, Marijn van Klingeren, and Yariv Tsfati. 2017. 'Selective Exposure, Political Polarization, and Possible Mediators: Evidence from the Netherlands'. International Journal of Public Opinion Research 29 (2): 189-213.

Webster, James G., and Thomas B. Ksiazek. 2012. 'The Dynamics of Audience Fragmentation: Public Attention in an Age of Digital Media'. Journal of Communication 62 (1): 39-56.

Weeks, Brian E., Daniel S. Lane, Dam Hee Kim, Slgi S. Lee, and Nojin Kwak. 2017. 'Incidental Exposure, Selective Exposure, and Political Information Sharing: Integrating Online Exposure Patterns and Expression on Social Media'. Journal of Computer-Mediated Communication 22 (6): 363-79. 
Yang, JungHwan, Hernando Rojas, Magdalena Wojcieszak, Toril Aalberg, Sharon Coen, James Curran, Kaori Hayashi, et al. 2016. 'Why Are “Others” So Polarized? Perceived Political Polarization and Media Use in 10 Countries'. Journal of Computer-Mediated Communication 21 (5): 349-67.

Zuiderveen Borgesius, Frederick J., Damian Trilling, Judith Möller, Balázs Bodó, Claes H. de Vreese, and Natali Helberger. 2016. 'Should We Worry about Filter Bubbles?' Internet Policy Review 5 (1): 1-16. 


\section{Supplementary materials}

1. Comparison with other audience political leaning scores

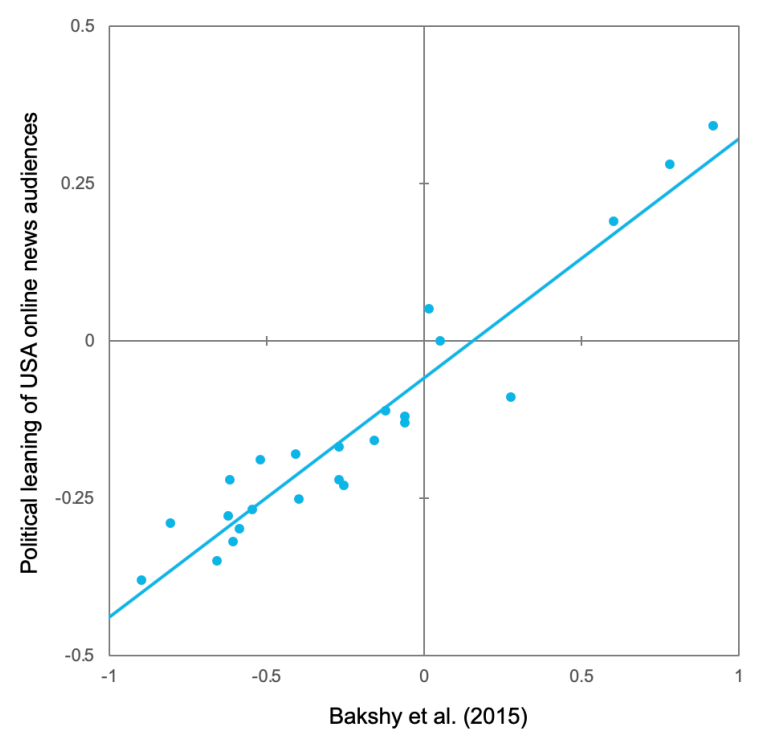

In order to better understand the reliability of our news outlet political leaning scores, we compare them with data from other sources. Unfortunately, to our knowledge there is no equivalent study that has produced scores across a range of countries and platforms. One recent set of high quality scores were produced by Bakshy et al. (2015) in their study of the Facebook news feed. They used Facebook data to produce scores for the top 500 news outlets. Because this study was based on tracking data, the scores only apply to online outlets, and almost all of these are US-based. When we compare our scores for all 24 online outlets in the US to those produced by Bakshy et al. (2015) using a Pearson correlation test, we find a very strong positive correlation between the two $(r=.96, p<.001)$. In line with what we expect from survey data, the trend line in the figure above possibly indicates that our scores skew slightly towards left-leaning responses. But on the whole, we believe that the test shows that the scores (in the US at least) are in line with those produced by other studies. 


\section{Survey questions}

All data used in this study comes from the following four survey questions, that were asked as part of a longer survey of news use. All survey questions were translated into the most widely-spoken language in each country. Underlining denotes text that was adapted in each country to provide relevant examples. Examples used in the UK are shown below.

\subsection{Questions about politics}

Q1F. Some people talk about 'left', 'right' and 'centre' to describe parties and politicians.

(Generally socialist parties would be considered 'left wing' whilst conservative parties would be considered 'right wing'). With this in mind, where would you place yourself on the following scale?

-0.5 : Very left-wing

-0.5: Fairly left-wing

-0.5: Slightly left-of-centre

0: Centre

0.5: Slightly right-of-centre

0.5: Fairly right-wing

0.5: Very right-wing

998: Don't know (excluded from the analysis)

Table 1. Descriptive statistics for Q1F

\begin{tabular}{|c|c|c|c|}
\hline Country & Mean & $\mathrm{SD}$ & $\mathrm{N}$ \\
\hline Australia & -.05 & .39 & 1670 \\
\hline Czech Republic & .04 & .40 & 1724 \\
\hline Germany & -.05 & .40 & 1723 \\
\hline Finland & -.02 & .47 & 1488 \\
\hline France & -.01 & .47 & 1487 \\
\hline Ireland & -.10 & .39 & 1674 \\
\hline Italy & -.06 & .44 & 1574 \\
\hline Netherlands & -.03 & .45 & 1579 \\
\hline Poland & .00 & .40 & 1579 \\
\hline Spain & -.15 & .42 & 1770 \\
\hline UK & -.08 & .44 & 1788 \\
\hline USA & .00 & .44 & 1982 \\
\hline
\end{tabular}




\subsection{Questions about news use}

Q5A. Which of the following brands have you used to access news **offline** in the last week (via **TV, radio, print, and other traditional media)?** Please select all that apply.

Q5B. Which of the following brands have you used to access news **online** in the last week (via ** websites, apps, social media, and other forms of Internet access**)? Please select all that apply.

See section 4 for descriptive statistics. 


\subsection{Questions on online news access}

Q10. Thinking about how you got news online (via computer, mobile or any device) in the last week, which were the ways in which you came across news stories? Please select all that apply.

- Went directly to a news website or app (e.g. BBC News, Guardian, Mail online, Huffington Post)

- Used a search engine (e.g. Google, Bing) and typed in a keyword for the name of a particular website

- Used a search engine (e.g. Google, Bing) and typed in a keyword about a particular news story

- Used a newsreader site or 'app' that aggregates news links (e.g. Flipboard, Apple News, SmartNews)

- Used social media and came across news that way (e.g. Facebook, Twitter, LinkedIn)

- Got news via an email newsletter or email alert

- Received a news alert on my mobile phone/tablet (e.g. via SMS, app, notification centre)

- Other

- Don’t know

- I haven't used online news in the last week 
Table 2. Descriptive statistics for Q10

\begin{tabular}{|c|c|c|c|c|c|c|c|c|c|c|c|c|}
\hline Country & 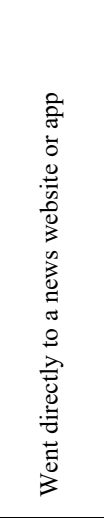 & 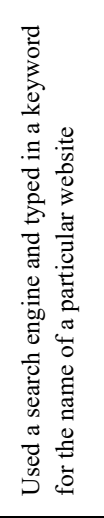 & 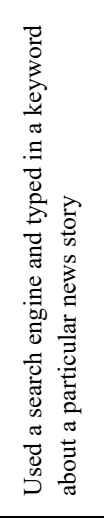 & 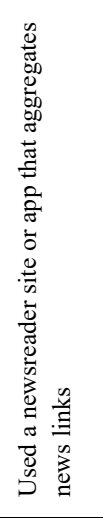 & 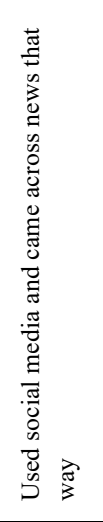 & 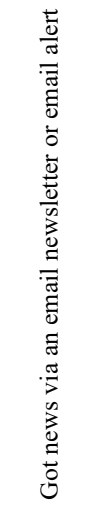 & 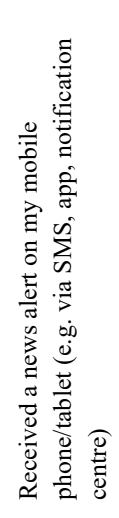 & 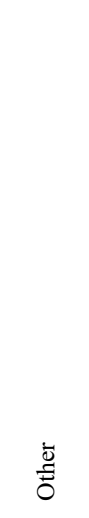 & $\begin{array}{l}z \\
0 \\
\bar{\Xi} \\
\pm \\
\dot{0} \\
\overline{0}\end{array}$ & 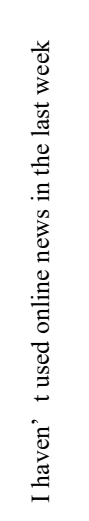 & 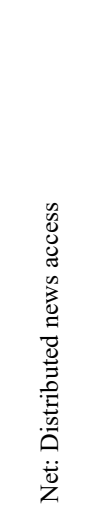 & $\mathrm{z}$ \\
\hline Poland & 37.61 & 45.50 & 33.83 & 7.55 & 40.64 & 12.17 & 8.74 & 1.04 & 5.86 & 0.45 & 60.56 & 2013 \\
\hline Czech Republic & 42.39 & 46.63 & 29.96 & 15.73 & 34.25 & 16.03 & 4.34 & 1.40 & 5.94 & 0.25 & 57.91 & 2003 \\
\hline Italy & 37.35 & 40.83 & 32.42 & 7.71 & 34.51 & 14.42 & 9.75 & 1.44 & 5.32 & 0.25 & 57.48 & 2011 \\
\hline Spain & 37.69 & 40.23 & 25.92 & 9.27 & 40.68 & 15.25 & 11.91 & 2.44 & 5.14 & 0.90 & 57.38 & 2006 \\
\hline USA & 40.64 & 25.69 & 25.17 & 8.90 & 42.05 & 24.28 & 19.92 & 4.80 & 8.90 & 1.32 & 56.90 & 2239 \\
\hline Ireland & 44.55 & 27.82 & 21.43 & 6.10 & 34.72 & 12.64 & 12.54 & 2.90 & 6.19 & 0.80 & 50.40 & 2002 \\
\hline Australia & 34.13 & 24.55 & 20.36 & 10.03 & 34.33 & 19.06 & 12.58 & 4.14 & 10.63 & 2.30 & 49.95 & 2004 \\
\hline Netherlands & 48.65 & 19.14 & 14.36 & 7.33 & 32.65 & 18.79 & 15.85 & 3.14 & 10.42 & 1.60 & 44.92 & 2006 \\
\hline France & 27.95 & 31.70 & 24.00 & 6.60 & 25.70 & 22.30 & 15.20 & 2.25 & 10.70 & 2.90 & 44.40 & 2000 \\
\hline Finland & 67.07 & 16.29 & 9.65 & 9.67 & 29.00 & 9.22 & 6.33 & 2.19 & 9.22 & 0.30 & 40.31 & 2007 \\
\hline Germany & 34.34 & 21.97 & 18.48 & 7.95 & 21.92 & 16.44 & 8.92 & 3.98 & 19.25 & 2.28 & 39.04 & 2062 \\
\hline UK & 56.96 & 15.44 & 11.51 & 6.72 & 29.88 & 9.47 & 12.03 & 3.93 & 10.37 & 2.32 & 38.45 & 2029 \\
\hline
\end{tabular}

Note. All columns apart from ' $\mathrm{N}$ ' showing per cent. 'Net: Distributed news access' is the proportion that used any of the following three methods of online news access: 'Used a search engine and typed in a keyword about a particular news story', 'Used a newsreader site or app that aggregates news links', and 'Used social media and came across news that way'. 


\section{Online and offline news audience polarization maps}

USA (online)

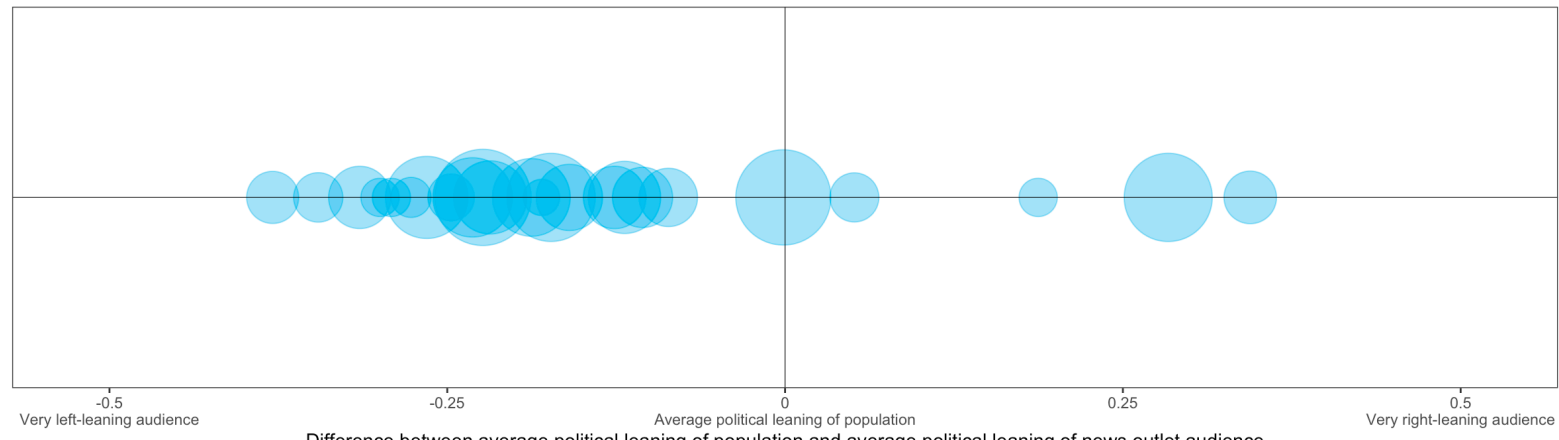

Difference between average political leaning of population and average political leaning of news outlet audience

USA (offline)

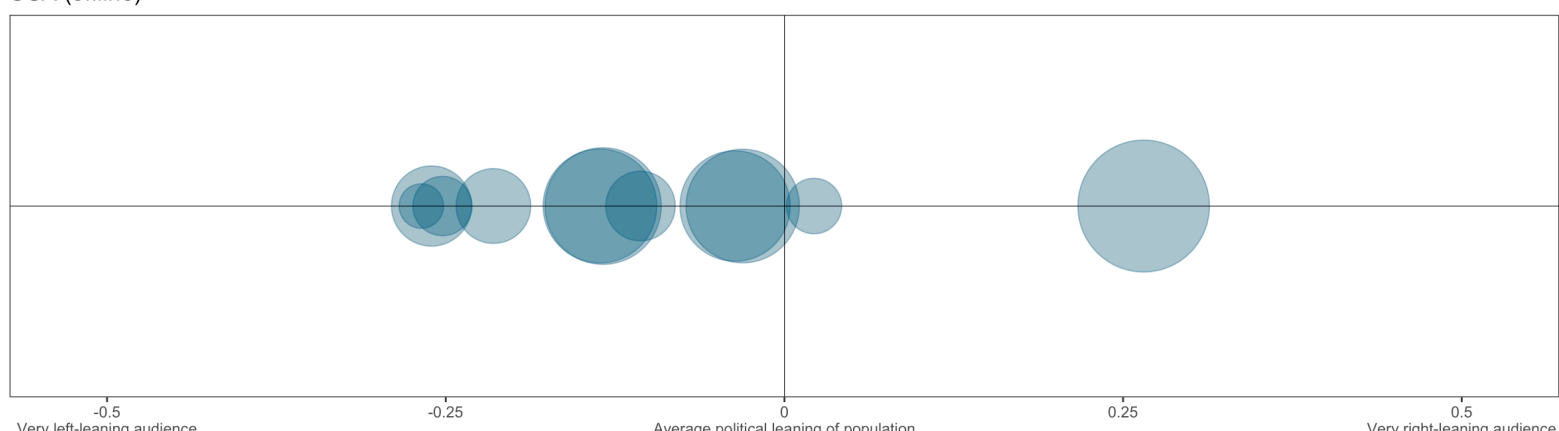

Difference between average political leaning of population and average political leaning of news outlet audience

UK (online)

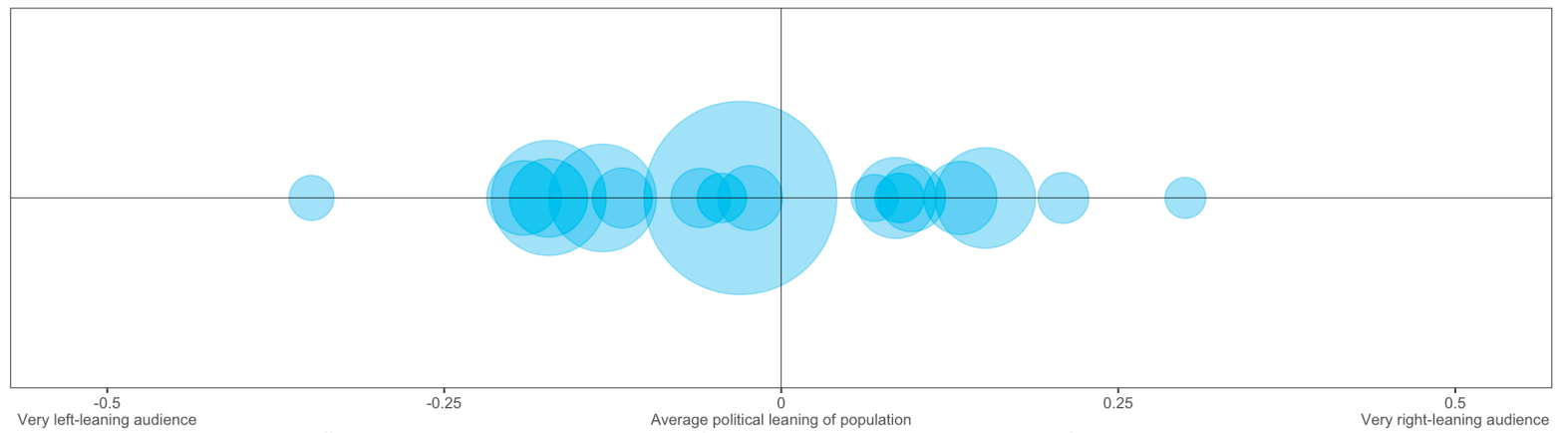

Difference between average political leaning of population and average political leaning of news outlet audience

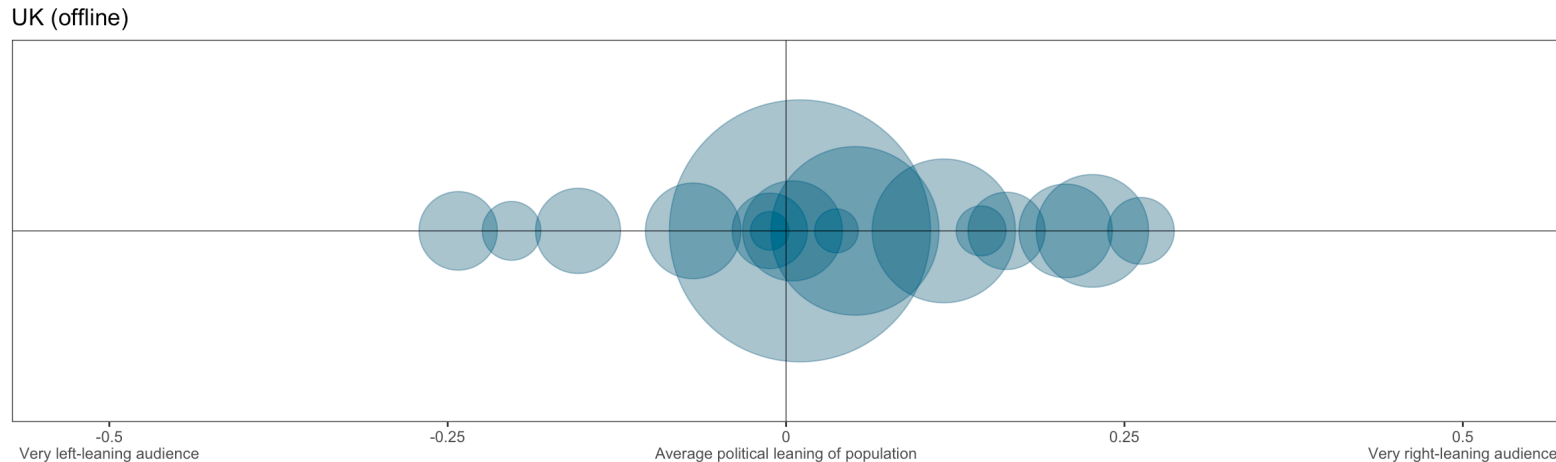

Difference between average political leaning of population and average political leaning of news outlet audience 
France (online)

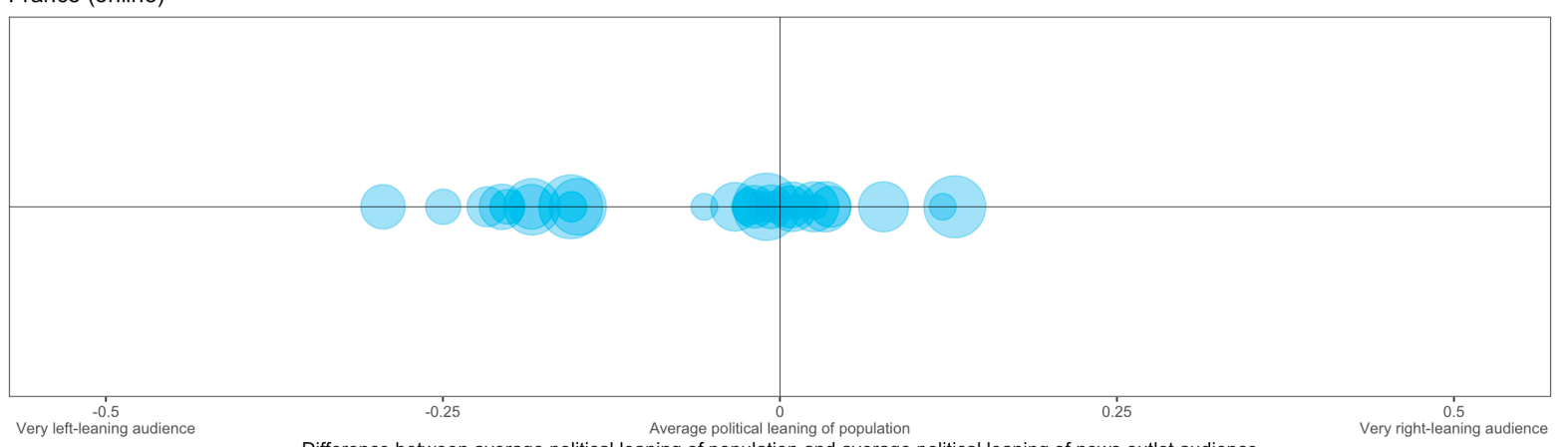

Difference between average political leaning of population and average political leaning of news outlet audience

France (offline)

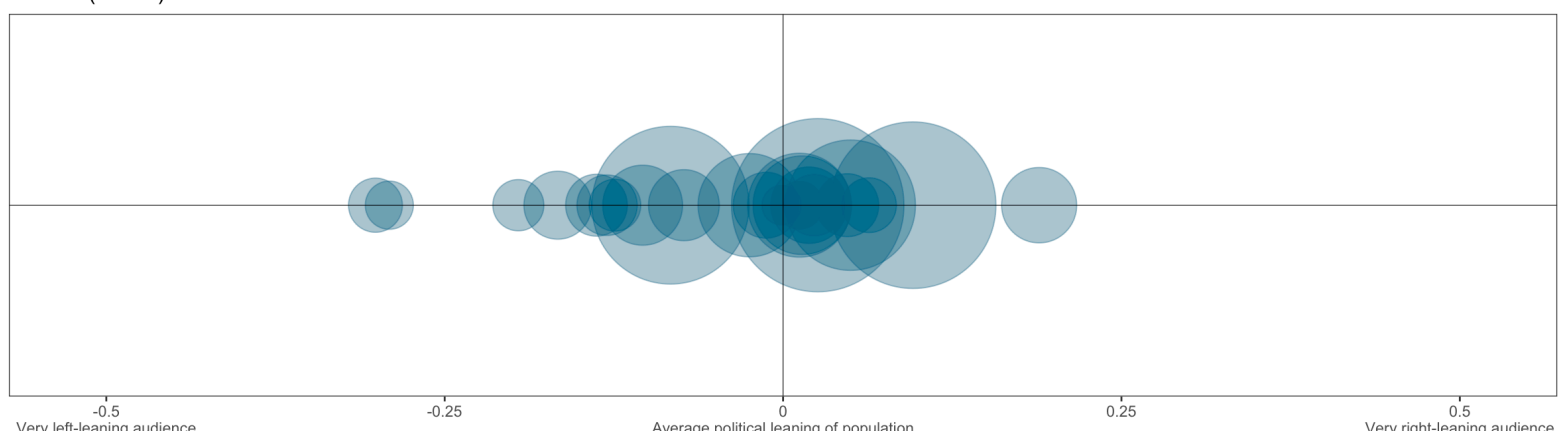

Difference between average political leaning of population and average political leaning of news outlet audience

Spain (online)

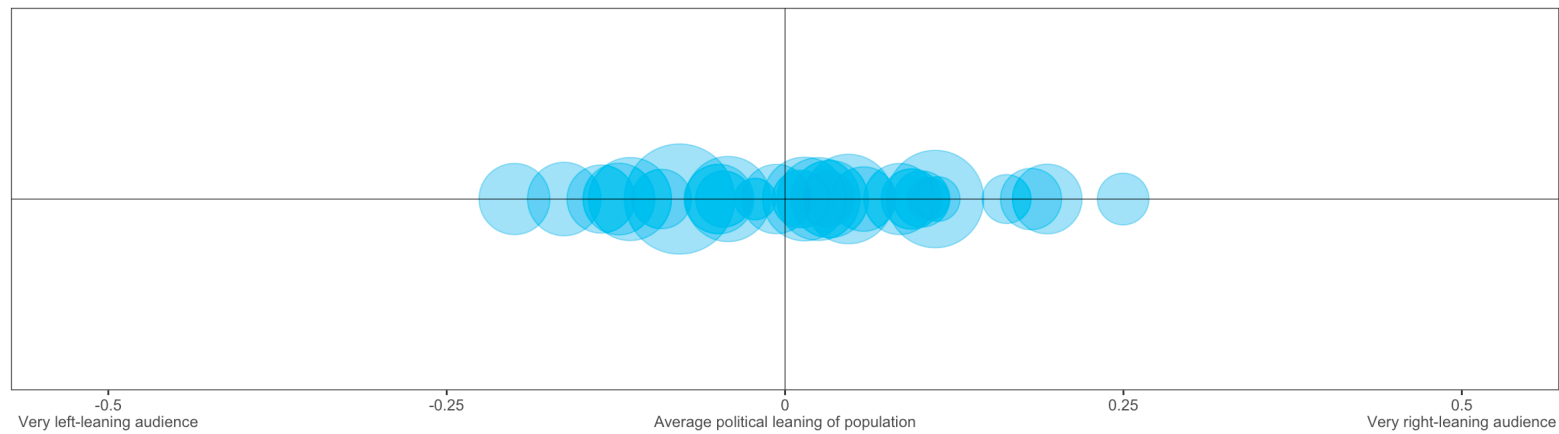

Difference between average political leaning of population and average political leaning of news outlet audience

Spain (offline)

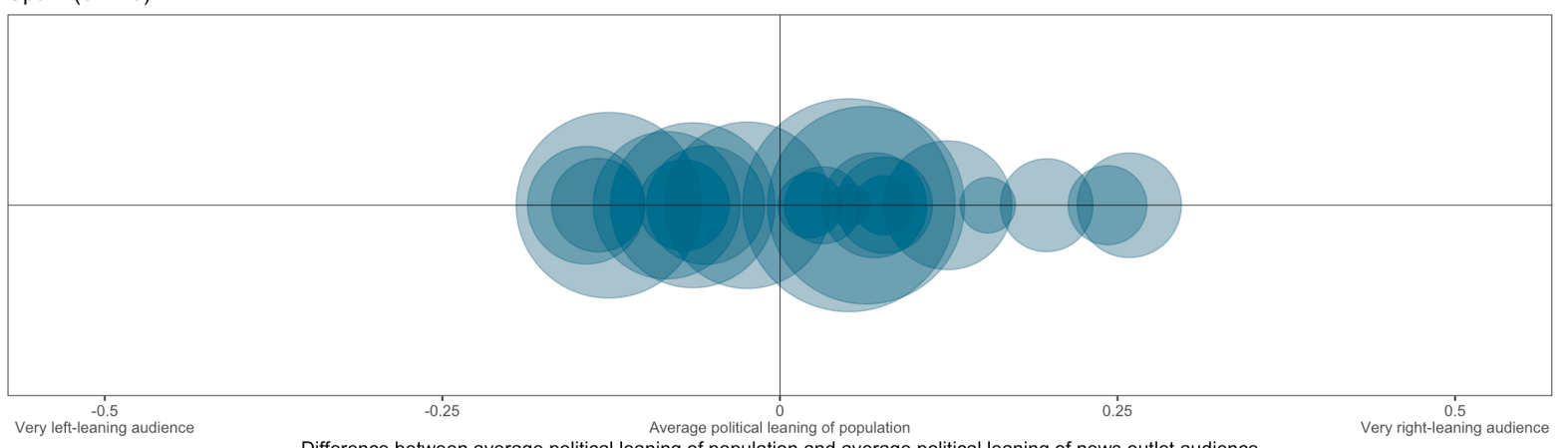

Difference between average political leaning of population and average political leaning of news outlet audience 


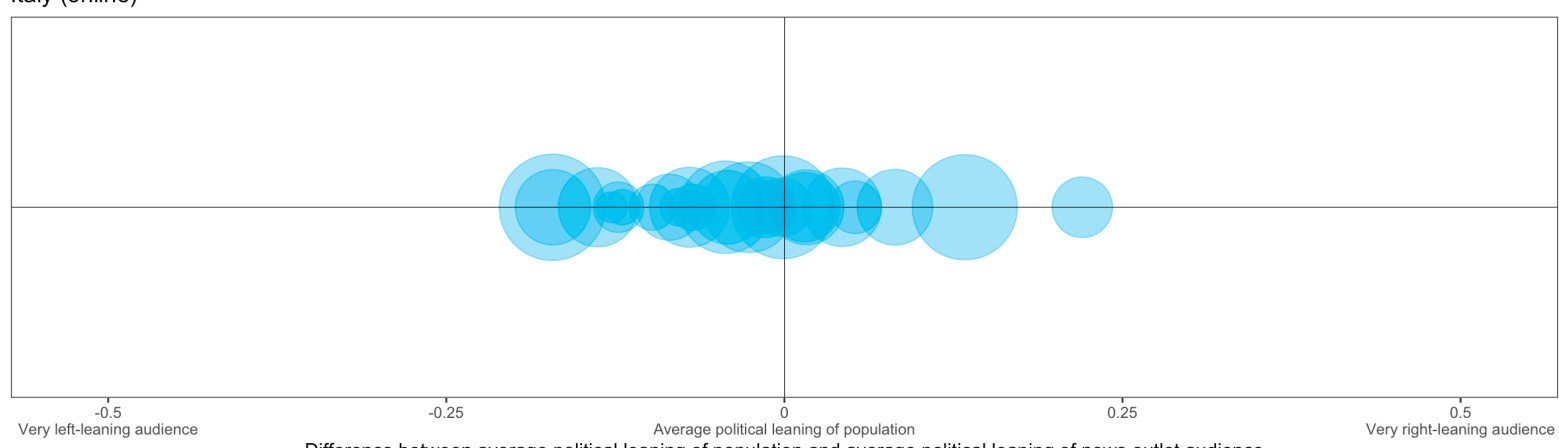

Difference between average political leaning of population and average political leaning of news outlet audience

Italy (offline)

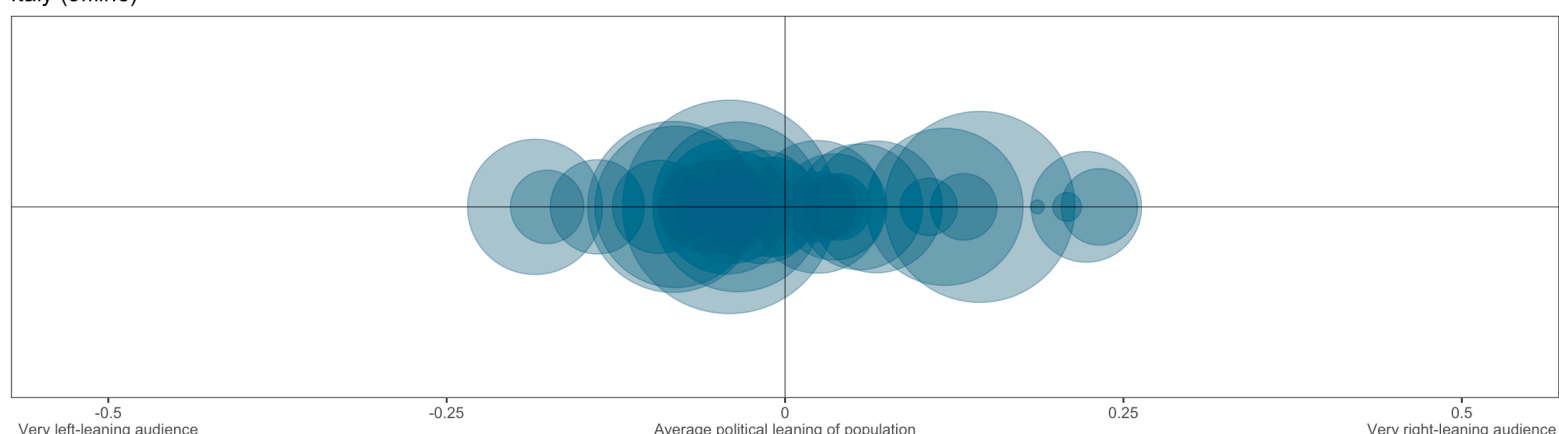

Difference between average political leaning of population and average political leaning of news outlet audience

Poland (online)

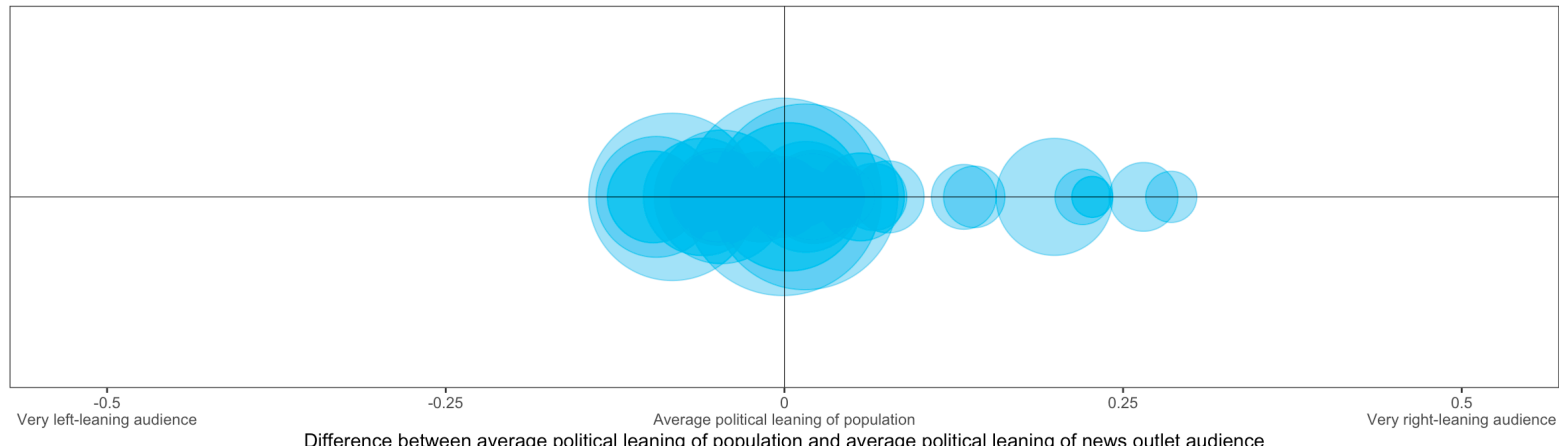

Poland (offline)

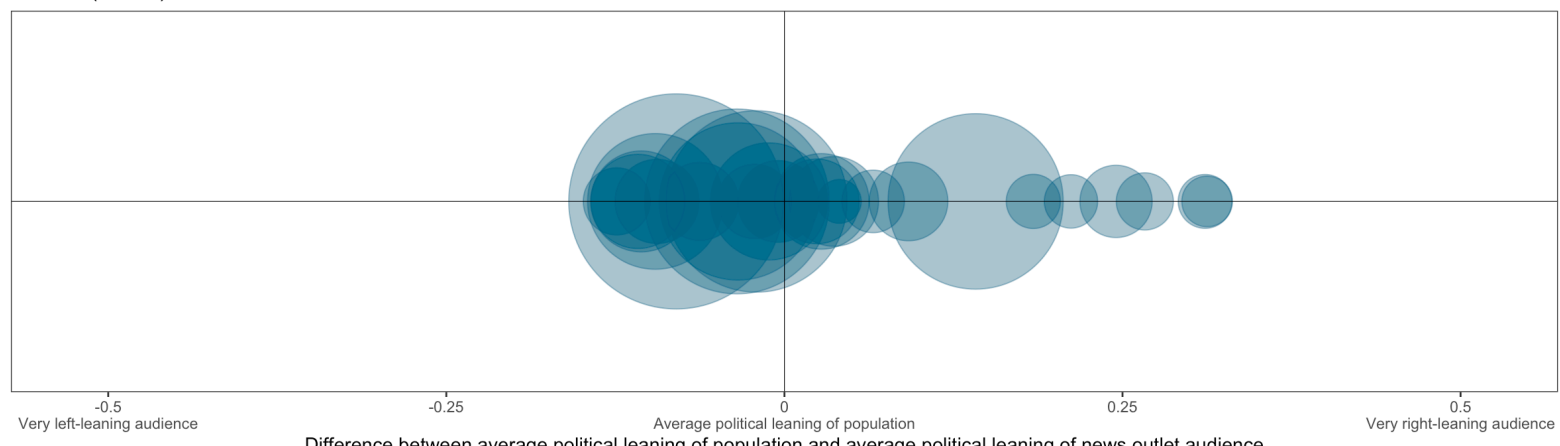

Difference between average political leaning of population and average political leaning of news outlet audience 


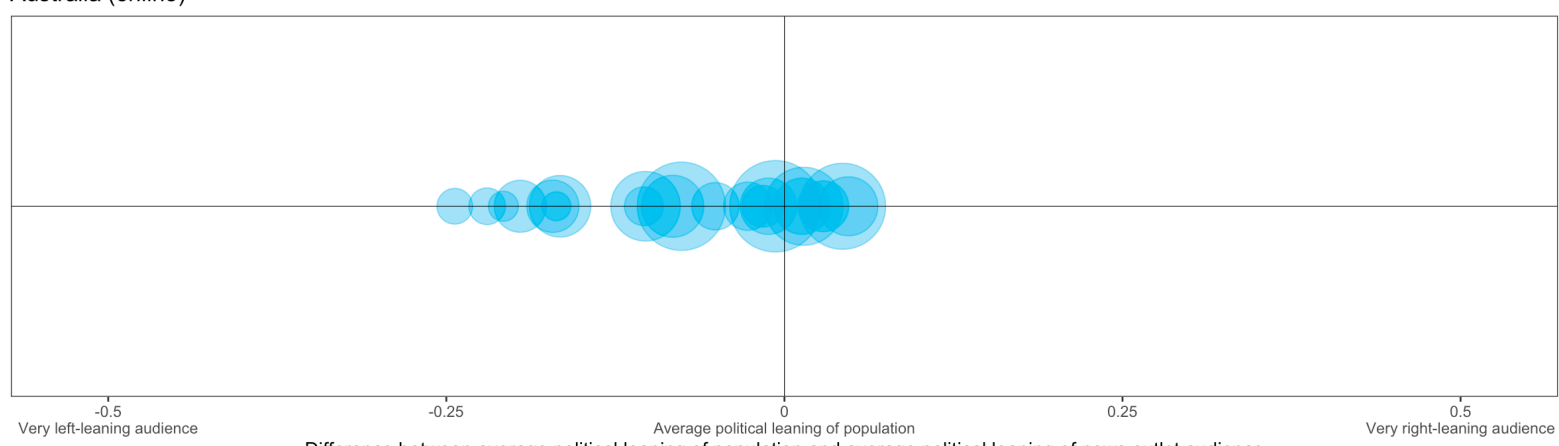

Difference between average political leaning pof population and average political leaning of news outlet audience

Australia (offline)

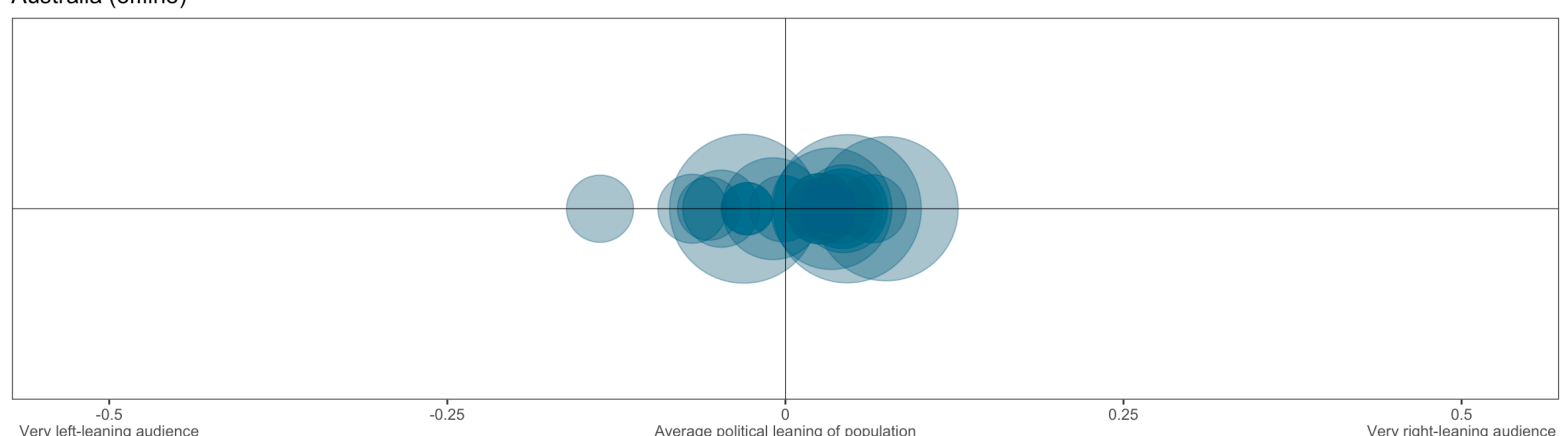

Difference between average political leaning of population and average political leaning of news outlet audience

$\stackrel{0.5}{0}$ ary right-leaning audience

Netherlands (online)

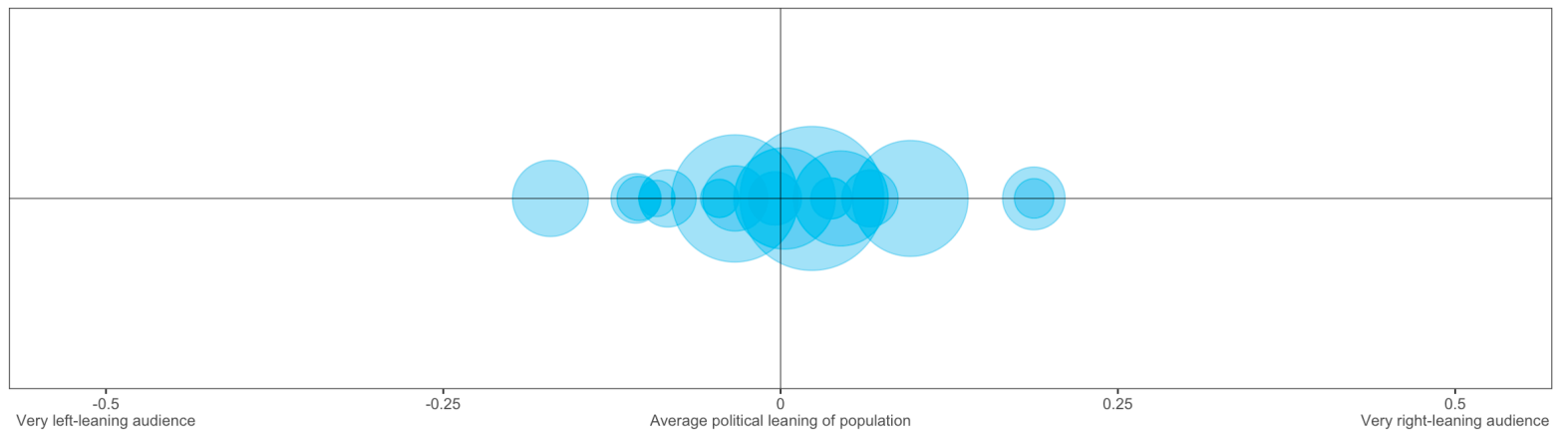

Difference between average political leaning of population and average political leaning of news outlet audience

Netherlands (offline)

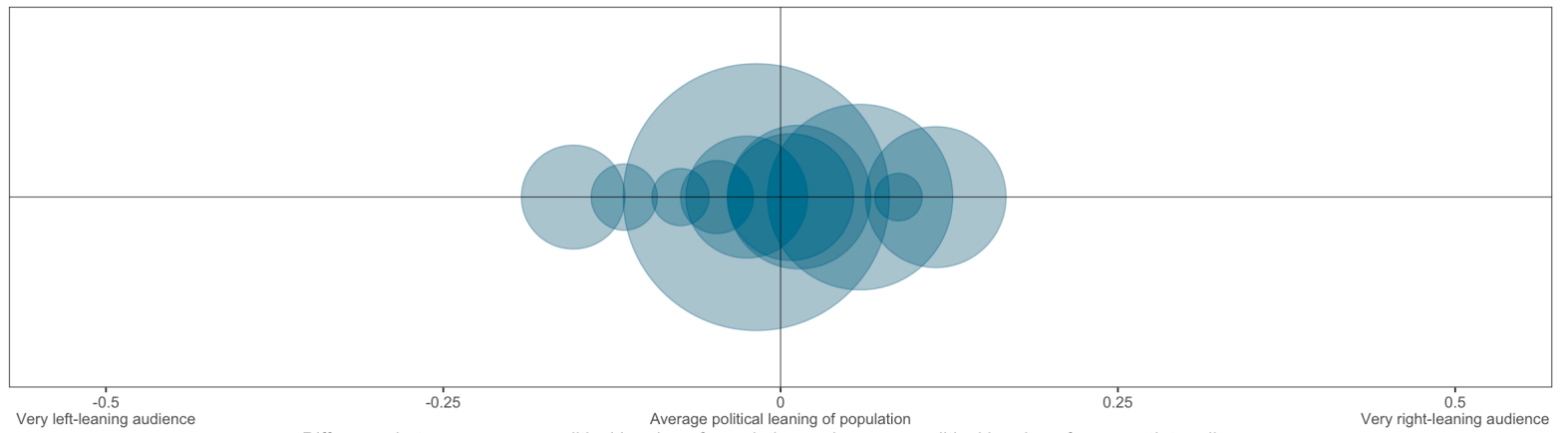


Finland (online)

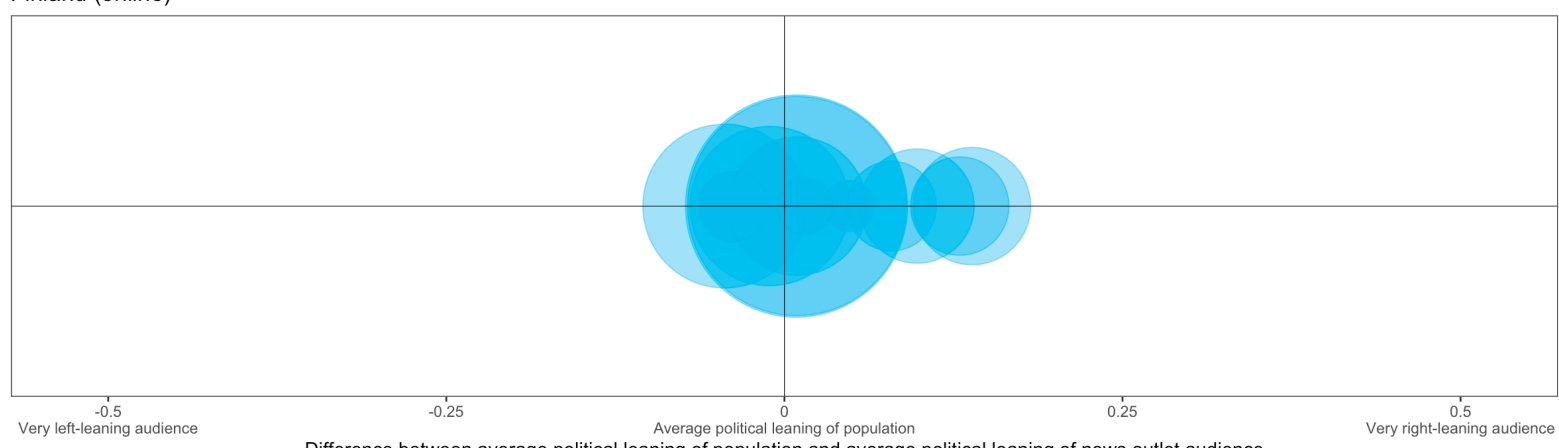

Difference between average political leaning of population and average political leaning of news outlet audience

Finland (offline)

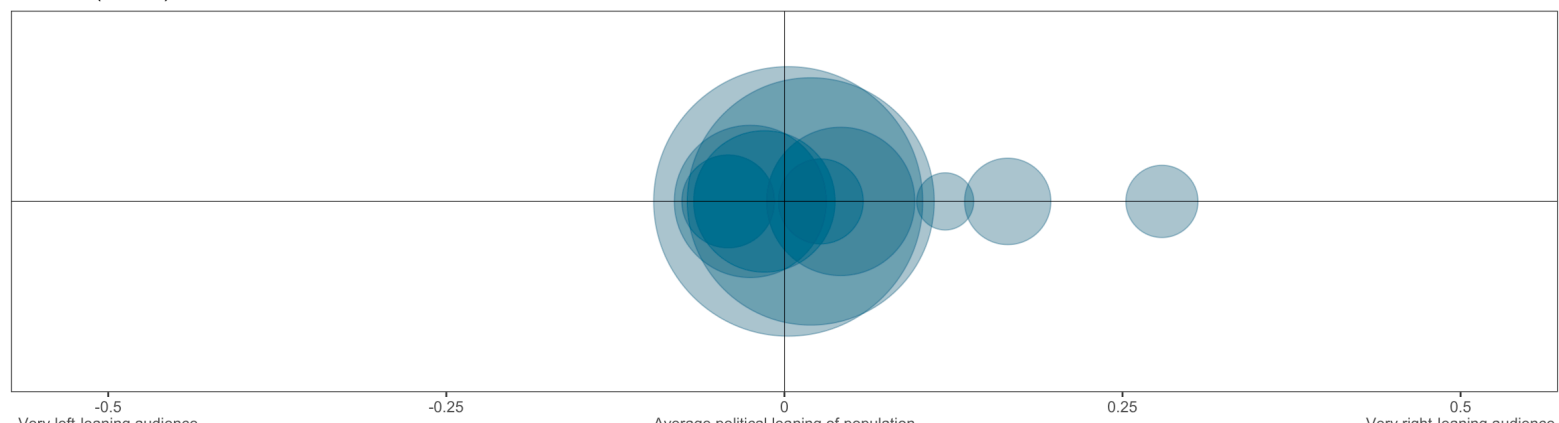

Very left-leaning audience

Difference between average political leaning of population and average political leaning of news outlet audience

$\stackrel{0.5}{\text { Very right-leaning audienc }}$

Czech Republic (online)

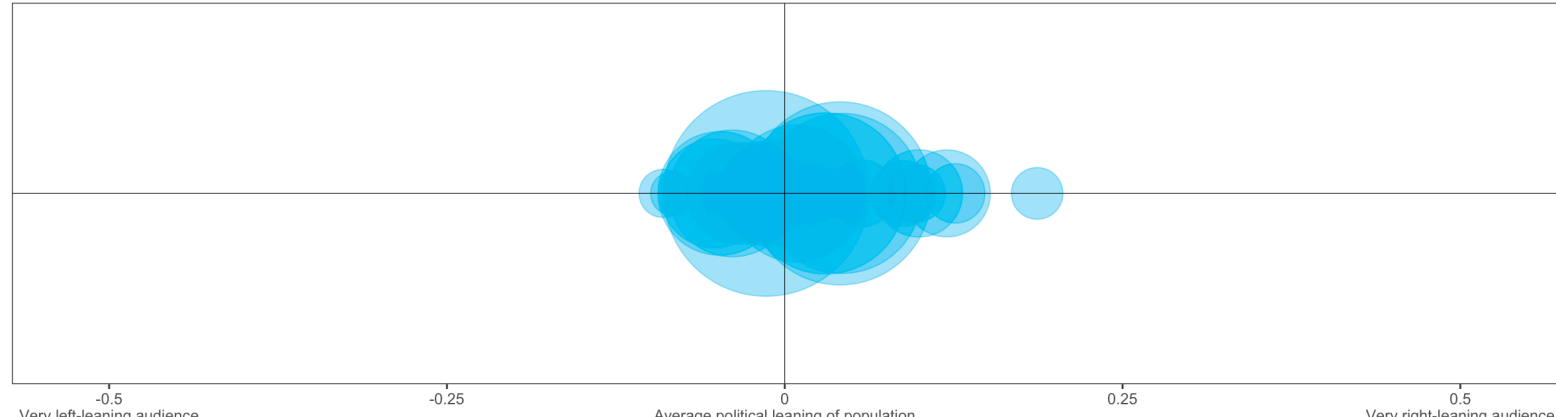

Difference between average political leaning of population and average political leaning of news outlet audience

Czech Republic (offline)

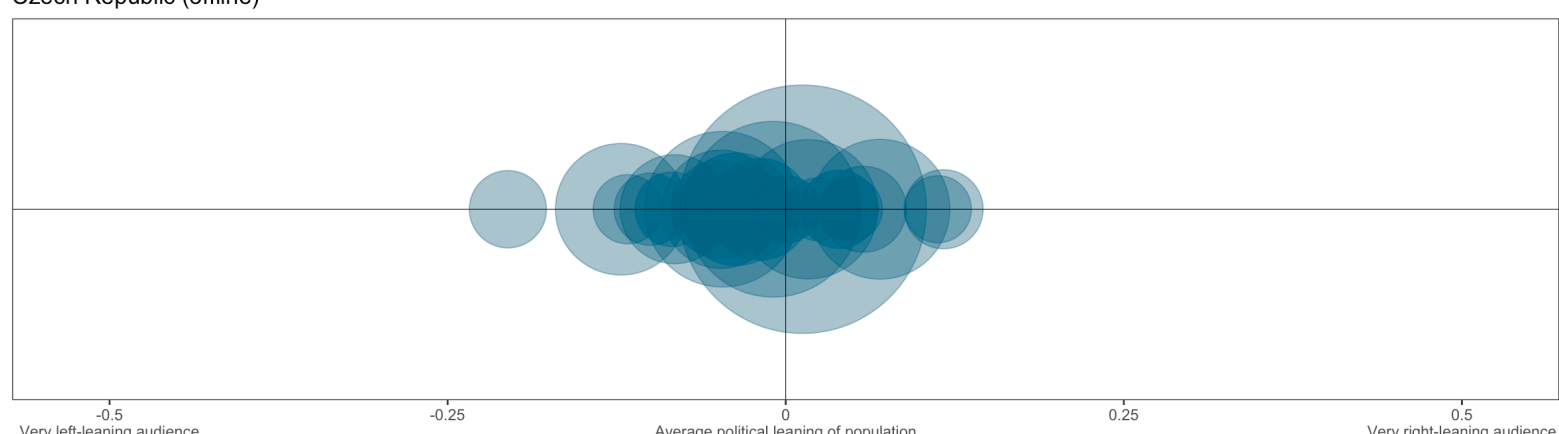

Difference between average political leaning of population and average political leaning of news outlet audience 


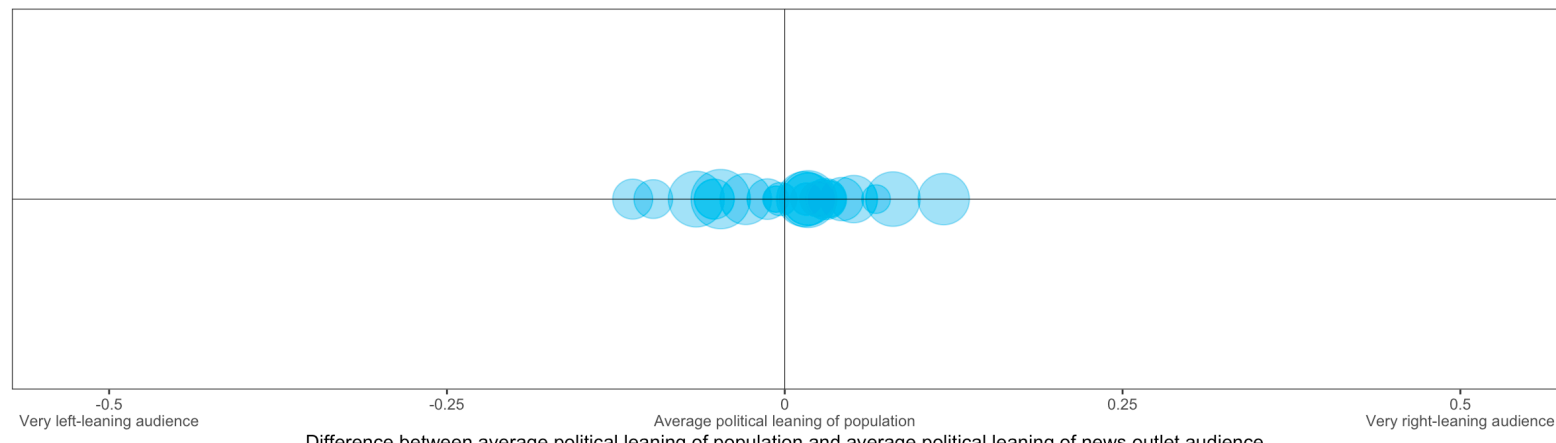

Difference between average political leaning of population and average political leaning of news outlet audience

Germany (offline)

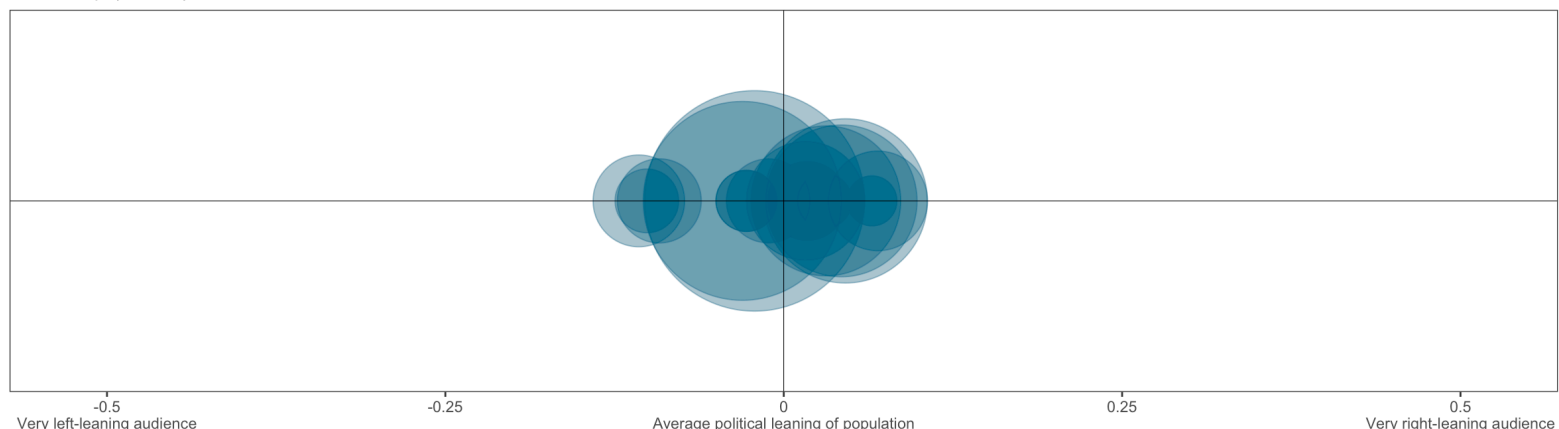

Difference between average political leaning of population and average political leaning of news outlet audience

Ireland (online)

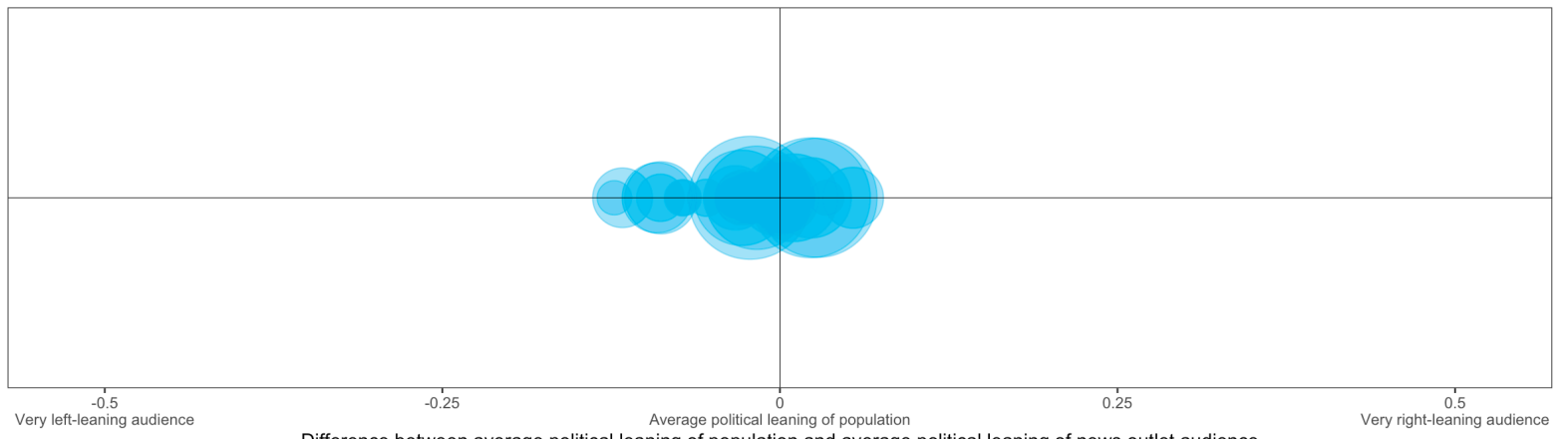

Difference between average political leaning of population and average political leaning of news outlet audience

Ireland (offline)

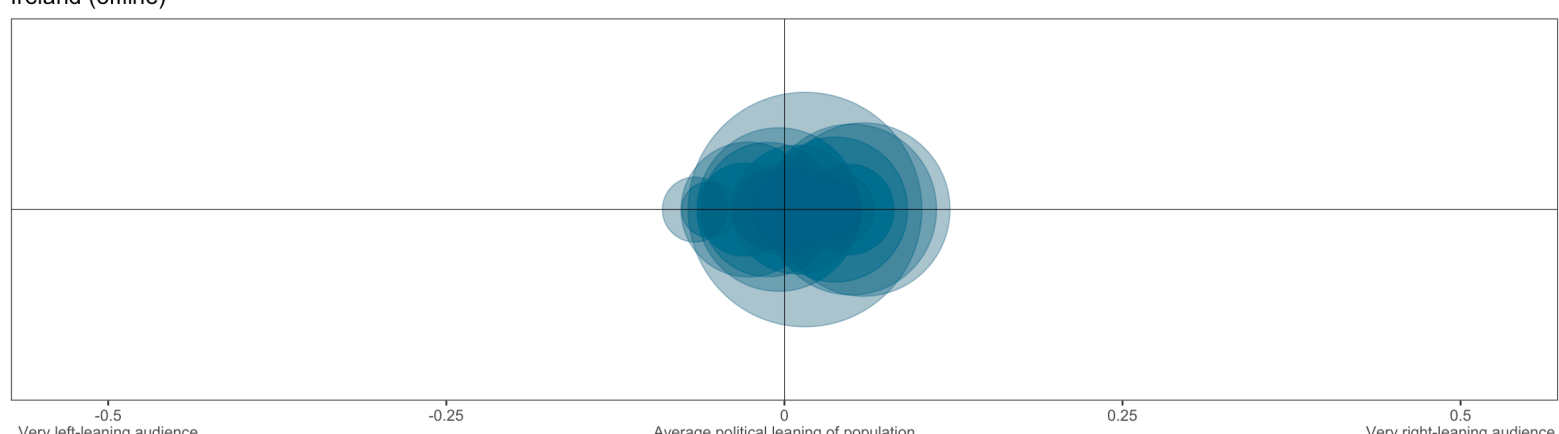

Difference between average political leaning of population and average political leaning of news outlet audience 
4. Full outlet reach and political leaning scores

Table 3. Australia news outlets included

\begin{tabular}{|c|c|c|c|c|c|c|}
\hline Name & $\begin{array}{c}\text { Cross-platform } \\
\text { weekly reach }(\%)\end{array}$ & $\begin{array}{c}\text { Cross-platform } \\
\text { audience political } \\
\text { leaning score }\end{array}$ & $\begin{array}{c}\text { Offline weekly reach } \\
(\%)\end{array}$ & $\begin{array}{c}\text { Offline audience } \\
\text { political leaning score }\end{array}$ & $\begin{array}{c}\text { Online weekly reach } \\
(\%)\end{array}$ & $\begin{array}{c}\text { Online audience } \\
\text { political leaning score }\end{array}$ \\
\hline Channel 7/Yahoo! News & 47.51 & .04 & 38.72 & .05 & 17.37 & .01 \\
\hline Channel 9/MSN News & 46.11 & .06 & 36.63 & .08 & 21.11 & .04 \\
\hline ABC News & 45.76 & -.04 & 39.07 & -.03 & 22.26 & -.08 \\
\hline Channel TEN News & 29.79 & .02 & 25.89 & .03 & 6.54 & -.03 \\
\hline News.com.au & 23.90 & -.01 & 0 & NA & 23.90 & -.01 \\
\hline Sydney Morning Herald & 18.56 & -.08 & 10.32 & -.05 & 13.72 & -.10 \\
\hline Herald Sun & 17.86 & .02 & 13.42 & .04 & 9.83 & .05 \\
\hline Daily Telegraph & 15.82 & .01 & 11.03 & .04 & 8.88 & .01 \\
\hline The Age & 14.32 & -.07 & 8.23 & -.07 & 10.87 & -.08 \\
\hline The Australian & 13.97 & -.01 & 8.63 & .03 & 8.93 & -.01 \\
\hline Sky News & 12.38 & .05 & 7.98 & .06 & 7.24 & .03 \\
\hline Courier Mail & 10.98 & -.04 & 7.59 & .00 & 6.29 & -.05 \\
\hline HuffPost & 10.68 & -.17 & 0 & NA & 10.68 & -.17 \\
\hline Australian Financial Review & 7.74 & -.03 & 4.69 & -.03 & 4.79 & -.02 \\
\hline Guardian Australia & 7.69 & -.17 & 0 & NA & 7.69 & -.17 \\
\hline BuzzFeed News & 7.59 & -.20 & 0 & NA & 7.59 & -.20 \\
\hline The Advertiser & 6.84 & -.06 & 4.64 & -.03 & 4.14 & -.10 \\
\hline The Conversation & 3.69 & -.22 & 0 & NA & 3.69 & -.22 \\
\hline Vice News & 3.49 & -.24 & 0 & NA & 3.49 & -.24 \\
\hline Crikey & 2.45 & -.21 & 0 & NA & 2.45 & -.21 \\
\hline Junkee & 2.25 & -.17 & 0 & NA & 2.25 & -.17 \\
\hline SBS News & - & - & 18.11 & -.01 & - & - \\
\hline Prime7 News & - & - & 8.58 & .03 & - & - \\
\hline WIN Television News & - & - & 8.38 & .04 & - & - \\
\hline Triple J News & - & - & 7.78 & -.14 & - & - \\
\hline Radio National News & - & - & 6.84 & -.06 & - & - \\
\hline Triple M News & - & - & 6.44 & .03 & - & - \\
\hline Southern Cross News & - & - & 4.59 & .04 & - & - \\
\hline KIIS News & - & - & 4.09 & .03 & - & - \\
\hline
\end{tabular}


Table 4. Czech Republic news outlets included

\begin{tabular}{|c|c|c|c|c|c|c|}
\hline Name & $\begin{array}{c}\text { Cross-platform } \\
\text { weekly reach }(\%)\end{array}$ & $\begin{array}{l}\text { Cross-platform } \\
\text { audience political } \\
\text { leaning score }\end{array}$ & $\begin{array}{c}\text { Offline weekly reach } \\
(\%)\end{array}$ & $\begin{array}{c}\text { Offline audience } \\
\text { political leaning score }\end{array}$ & $\begin{array}{c}\text { Online weekly reach } \\
(\%)\end{array}$ & $\begin{array}{c}\text { Online audience } \\
\text { political leaning score }\end{array}$ \\
\hline ČT24 & 68.30 & .02 & 65.40 & .01 & 23.81 & .01 \\
\hline Seznam.cz/zpravy News & 54.12 & -.01 & 0 & NA & 54.12 & -.01 \\
\hline Nova & 43.19 & -.02 & 32.60 & -.01 & 20.42 & -.04 \\
\hline Prima News & 36.20 & -.04 & 25.51 & -.05 & 19.42 & -.05 \\
\hline Pravo & 36.20 & .01 & 6.19 & -.21 & 32.70 & .04 \\
\hline Aktualne.cz & 33.10 & .03 & 0 & NA & 30.50 & .03 \\
\hline Metro & 15.08 & -.02 & 13.28 & -.04 & 4.24 & .02 \\
\hline Hospodarske Noviny & 14.28 & .09 & 6.49 & .12 & 9.58 & .10 \\
\hline Super.cz & 14.03 & -.01 & 0 & NA & 14.03 & -.01 \\
\hline Lidove Noviny & 13.88 & .10 & 6.34 & .04 & 9.54 & .12 \\
\hline Parlamentnilisty.cz & 13.23 & -.02 & 0 & NA & 13.23 & -.02 \\
\hline Tyden & 9.79 & .02 & 4.69 & .00 & 6.69 & .04 \\
\hline Reflex & 8.34 & .08 & 4.64 & .11 & 5.34 & .09 \\
\hline Ekonom & 4.24 & .07 & $<2$ & NA & 3.10 & .02 \\
\hline Echo & 3.50 & .17 & $<2$ & NA & 3.29 & .19 \\
\hline Ceskenoviny.cz & 3.40 & -.01 & 0 & NA & 3.40 & -.01 \\
\hline Euro & 2.90 & .14 & $<2$ & NA & $<2$ & NA \\
\hline Forbes & 2.90 & .06 & $<2$ & NA & $<2$ & NA \\
\hline Britskelisty.cz & 2.85 & -.09 & 0 & NA & 2.85 & -.09 \\
\hline EuroZpravy.cz & 2.80 & .04 & 0 & NA & 2.80 & .04 \\
\hline Yahoo! News & 2.30 & -.08 & 0 & NA & 2.30 & -.08 \\
\hline Ac24.cz & 2.30 & -.05 & 0 & NA & 2.30 & -.05 \\
\hline
\end{tabular}


Radio Impuls News

TV Barrandov News

Frekvence 1 News

Evropa 2 News

7.69

4.94

Blanik News 
Table 5. Germany news outlets included

\begin{tabular}{|c|c|c|c|c|c|c|}
\hline Name & $\begin{array}{c}\text { Cross-platform } \\
\text { weekly reach }(\%)\end{array}$ & $\begin{array}{l}\text { Cross-platform } \\
\text { audience political } \\
\text { leaning score }\end{array}$ & $\begin{array}{c}\text { Offline weekly reach } \\
(\%)\end{array}$ & $\begin{array}{c}\text { Offline audience } \\
\text { political leaning score }\end{array}$ & $\begin{array}{c}\text { Online weekly reach } \\
(\%)\end{array}$ & $\begin{array}{c}\text { Online audience } \\
\text { political leaning score }\end{array}$ \\
\hline ARD Tagesschau & 59.99 & -.03 & 57.95 & -.02 & 13.58 & -.07 \\
\hline ZDF Heute & 48.16 & -.03 & 47.09 & -.03 & 7.23 & -.01 \\
\hline RTL Aktuell & 32.93 & .05 & 32.06 & .05 & 4.27 & .02 \\
\hline $\mathrm{N} 24$ & 32.01 & .04 & 27.35 & .04 & 11.49 & .13 \\
\hline n-tv & 31.04 & .02 & 26.67 & .03 & 12.03 & .02 \\
\hline Der Spiegel & 22.16 & -.07 & 9.89 & -.11 & 15.42 & -.05 \\
\hline Bild & 18.57 & .06 & 11.69 & .07 & 9.75 & .05 \\
\hline Sat.1 Nachrichten & 17.90 & .01 & 16.59 & .02 & 2.86 & -.01 \\
\hline Focus & 17.27 & .04 & 8.24 & -.01 & 12.95 & .08 \\
\hline t-online & 14.16 & .02 & 0 & NA & 14.16 & .02 \\
\hline Web.de & 13.14 & .01 & 0 & NA & 13.14 & .01 \\
\hline Stern & 13.00 & -.07 & 8.29 & -.09 & 6.89 & -.05 \\
\hline Gmx.de & 11.30 & -.03 & 0 & NA & 11.30 & -.03 \\
\hline Die Welt & 10.28 & .03 & 3.44 & .03 & 8.10 & .04 \\
\hline Süddeutsche Zeitung & 9.79 & -.11 & 4.70 & -.10 & 6.89 & -.11 \\
\hline Die ZEIT & 9.17 & -.07 & 4.32 & -.03 & 6.45 & -.09 \\
\hline FAZ & 7.52 & -.03 & 4.32 & -.03 & 4.66 & .00 \\
\hline Huffington Post & 7.23 & .03 & 0 & NA & 7.23 & .03 \\
\hline Yahoo! News & 6.01 & .03 & 0 & NA & 6.01 & .03 \\
\hline Handelsblatt & 5.29 & .05 & 2.86 & .07 & 3.44 & .07 \\
\hline MSN News & 5.04 & .02 & 0 & NA & 5.04 & .02 \\
\hline ProSieben Newstime & - & - & 7.23 & .02 & - & - \\
\hline
\end{tabular}


Table 6. Spain news outlets included

\begin{tabular}{|c|c|c|c|c|c|c|}
\hline Name & $\begin{array}{c}\text { Cross-platform } \\
\text { weekly reach }(\%)\end{array}$ & $\begin{array}{c}\text { Cross-platform } \\
\text { audience political } \\
\text { leaning score }\end{array}$ & $\begin{array}{c}\text { Offline weekly reach } \\
(\%)\end{array}$ & $\begin{array}{c}\text { Offline audience } \\
\text { political leaning score }\end{array}$ & $\begin{array}{c}\text { Online weekly reach } \\
(\%)\end{array}$ & $\begin{array}{c}\text { Online audience } \\
\text { political leaning score }\end{array}$ \\
\hline Antena 3 News & 59.12 & .05 & 56.03 & .05 & 18.89 & .05 \\
\hline RTVE News & 50.50 & .07 & 48.21 & .06 & 11.86 & .09 \\
\hline LaSexta News & 45.31 & -.13 & 42.52 & -.13 & 12.66 & -.16 \\
\hline El Pais & 39.18 & -.07 & 26.67 & -.08 & 28.76 & -.08 \\
\hline Telecinco News & 36.89 & -.02 & 34.15 & -.02 & 11.27 & -.01 \\
\hline Cuatro News & 35.44 & -.06 & 33.55 & -.07 & 7.28 & -.05 \\
\hline El Mundo & 32.05 & .01 & 20.34 & .12 & 22.43 & .11 \\
\hline 20 Minutos & 26.76 & -.04 & 17.15 & -.06 & 17.10 & -.04 \\
\hline Marca & 21.24 & .05 & 13.46 & .07 & 16.15 & .03 \\
\hline Cadena SER News & 19.59 & -.13 & 16.95 & -.14 & 8.23 & -.09 \\
\hline $\mathrm{ABC}$ & 16.95 & .20 & 10.52 & .20 & 11.37 & .19 \\
\hline El Periódico & 16.70 & -.12 & 10.62 & -.14 & 10.87 & -.14 \\
\hline ElConfidencial.com & 16.50 & .01 & 0 & NA & 16.50 & .01 \\
\hline Eldiario.es & 16.25 & -.12 & 0 & NA & 16.25 & -.12 \\
\hline La Vanguardia & 15.65 & -.06 & 10.02 & -.07 & 11.31 & -.05 \\
\hline COPE News & 15.16 & .24 & 13.36 & .26 & 6.18 & .25 \\
\hline Yahoo! News & 14.06 & .03 & 0 & NA & 14.06 & .03 \\
\hline Onda Cero News & 12.81 & .09 & 11.27 & .08 & 4.59 & .11 \\
\hline La Razon & 12.66 & .19 & 7.58 & .24 & 8.77 & .18 \\
\hline El HuffPost & 12.06 & -.12 & 0 & NA & 12.06 & -.12 \\
\hline Público.es & 11.86 & -.20 & 0 & NA & 11.86 & -.20 \\
\hline As & 11.12 & .03 & 7.18 & .03 & 7.38 & .03 \\
\hline MSN News & 9.72 & .06 & 0 & NA & 9.72 & .06 \\
\hline OKDiario.com & 8.48 & .09 & 0 & NA & 8.48 & .09 \\
\hline Europa Press & 7.63 & .01 & 0 & NA & 7.63 & .01 \\
\hline Expansión & 7.48 & .16 & 3.69 & .15 & 5.53 & .16 \\
\hline Euronews & 7.43 & .00 & 5.09 & .02 & 3.94 & -.02 \\
\hline ElEspañol.com & 7.38 & .10 & 0 & NA & 7.38 & .10 \\
\hline Cinco Dias & 5.14 & .10 & 2.04 & .05 & 3.99 & .11 \\
\hline El Economista & - & - & 4.19 & .08 & - & - \\
\hline
\end{tabular}


Table 7. Finland news outlets included

\begin{tabular}{|c|c|c|c|c|c|c|}
\hline Name & $\begin{array}{c}\text { Cross-platform } \\
\text { weekly reach }(\%)\end{array}$ & $\begin{array}{l}\text { Cross-platform } \\
\text { audience political } \\
\text { leaning score }\end{array}$ & $\begin{array}{c}\text { Offline weekly reach } \\
(\%)\end{array}$ & $\begin{array}{c}\text { Offline audience } \\
\text { political leaning score }\end{array}$ & $\begin{array}{c}\text { Online weekly reach } \\
(\%)\end{array}$ & $\begin{array}{l}\text { Online audience } \\
\text { political leaning score }\end{array}$ \\
\hline Yle Uutiset & 71.85 & -.01 & 71.05 & .00 & 31.64 & -.04 \\
\hline MTV Uutiset & 65.07 & .01 & 59.79 & .02 & 22.42 & .01 \\
\hline Ilta-Sanomat & 63.78 & .00 & 22.52 & -.03 & 58.55 & .01 \\
\hline Iltalehti & 61.34 & .00 & 19.43 & -.02 & 56.90 & .01 \\
\hline Helsingin Sanomat & 39.76 & .02 & 21.38 & .04 & 29.95 & -.01 \\
\hline Kauppalehti & 19.18 & .13 & 7.18 & .17 & 16.14 & .14 \\
\hline Taloussanomat.fi & 15.30 & .10 & 0 & NA & 15.30 & .10 \\
\hline Talouselämä & 13.90 & .16 & 4.98 & .28 & 11.31 & .13 \\
\hline Uusisuomi.fi & 9.37 & .08 & 0 & NA & 9.37 & .08 \\
\hline Suomen Kuvalehti & 9.27 & .02 & 6.93 & .03 & 3.64 & .02 \\
\hline HS Uutiset Nelosella & 8.57 & -.05 & 8.27 & -.04 & $<2$ & NA \\
\hline MSN News & 5.68 & -.04 & 0 & NA & 5.68 & -.04 \\
\hline Maaseudun Tulevaisuus & 5.23 & .10 & 3.09 & .12 & 2.89 & .05 \\
\hline Hufvudstadsbladet & 2.94 & -.13 & $<2$ & NA & $<2$ & NA \\
\hline
\end{tabular}


Table 8. France news outlets included

\begin{tabular}{|c|c|c|c|c|c|c|}
\hline Name & $\begin{array}{c}\text { Cross-platform } \\
\text { weekly reach }(\%)\end{array}$ & $\begin{array}{l}\text { Cross-platform } \\
\text { audience political } \\
\text { leaning score }\end{array}$ & $\begin{array}{c}\text { Offline weekly reach } \\
(\%)\end{array}$ & $\begin{array}{c}\text { Offline audience } \\
\text { political leaning score }\end{array}$ & $\begin{array}{c}\text { Online weekly reach } \\
(\%)\end{array}$ & $\begin{array}{c}\text { Online audience } \\
\text { political leaning score }\end{array}$ \\
\hline BFMTV News & 47.35 & .03 & 45.40 & .03 & 9.65 & .03 \\
\hline TF1 News & 43.30 & .09 & 41.95 & .10 & 6.40 & .04 \\
\hline France Télévisions News & 42.60 & -.08 & 37.60 & -.08 & 12.35 & -.15 \\
\hline 20 Minutes & 27.40 & -.02 & 16.20 & .01 & 17.50 & -.01 \\
\hline M6 News & 27.10 & .05 & 25.60 & .05 & 3.60 & -.01 \\
\hline Le Monde & 20.40 & -.12 & 9.55 & -.10 & 15.75 & -.16 \\
\hline Le Figaro & 18.05 & .13 & 8.45 & .19 & 14.85 & .13 \\
\hline Itélé News & 17.15 & -.03 & 16.00 & -.03 & 2.60 & -.06 \\
\hline LCI News & 16.35 & .02 & 14.55 & .01 & 3.45 & -.01 \\
\hline Le Point & 13.00 & .07 & 5.85 & .05 & 9.60 & .08 \\
\hline L'Express & 12.65 & .01 & 5.50 & .02 & 9.40 & .01 \\
\hline Le HuffPost & 12.25 & -.18 & 0 & NA & 12.25 & -.18 \\
\hline L'Obs & 10.75 & -.15 & 5.40 & -.13 & 7.65 & -.18 \\
\hline Libération & 10.30 & -.22 & 4.30 & -.30 & 7.85 & -.21 \\
\hline France 24 News & 9.70 & -.10 & 6.85 & -.17 & 4.90 & -.02 \\
\hline Yahoo! News & 9.55 & .03 & 0 & NA & 9.55 & .03 \\
\hline L'internaute.com & 9.05 & -.03 & 0 & NA & 9.05 & -.03 \\
\hline Les Echos & 8.85 & .01 & 3.30 & .01 & 6.75 & .01 \\
\hline Direct Matin & 8.10 & -.02 & 6.40 & -.01 & 2.85 & -.01 \\
\hline Médiapart & 7.50 & -.30 & 0 & NA & 7.50 & -.30 \\
\hline MSN News & 7.25 & -.01 & 0 & NA & 7.25 & -.01 \\
\hline Courrier International & 7.00 & -.19 & 3.85 & -.20 & 4.55 & -.20 \\
\hline Aufeminin.com & 6.90 & -.02 & 0 & NA & 6.90 & -.02 \\
\hline Marianne & 6.65 & -.25 & 3.40 & -.29 & 4.65 & -.25 \\
\hline Canal+ News & 6.45 & -.14 & 5.65 & -.14 & $<2$ & NA \\
\hline Rue89 & 6.05 & -.22 & 0 & NA & 6.05 & -.22 \\
\hline BuzzFeed News & 3.40 & -.16 & 0 & NA & 3.40 & -.16 \\
\hline L'Opinion & 3.30 & -.02 & $<2$ & NA & 2.15 & .01 \\
\hline La Croix & 2.80 & .03 & $<2$ & NA & 2.05 & .03 \\
\hline Atlantico & 2.60 & .12 & 0 & NA & 2.60 & .12 \\
\hline Le Parisien & - & - & 8.65 & .02 & - & - \\
\hline Ouest France & - & - & 7.50 & -.07 & - & - \\
\hline La Voix du Nord & - & - & 4.40 & .06 & - & - \\
\hline Sud Ouest & - & - & 3.95 & -.12 & - & - \\
\hline
\end{tabular}


Table 9. Ireland news outlets included

\begin{tabular}{|c|c|c|c|c|c|c|}
\hline Name & $\begin{array}{c}\text { Cross-platform } \\
\text { weekly reach }(\%)\end{array}$ & $\begin{array}{l}\text { Cross-platform } \\
\text { audience political } \\
\text { leaning score }\end{array}$ & $\begin{array}{c}\text { Offline weekly reach } \\
(\%)\end{array}$ & $\begin{array}{c}\text { Offline audience } \\
\text { political leaning score }\end{array}$ & $\begin{array}{c}\text { Online weekly reach } \\
(\%)\end{array}$ & $\begin{array}{c}\text { Online audience } \\
\text { political leaning score }\end{array}$ \\
\hline RTÉ News & 67.18 & .01 & 61.64 & .02 & 30.62 & .02 \\
\hline Irish Independent & 42.56 & .03 & 32.57 & .05 & 30.32 & .03 \\
\hline Sky News & 37.26 & .05 & 33.57 & .06 & 13.59 & .02 \\
\hline BBC News & 35.66 & -.01 & 29.82 & .00 & 16.23 & .01 \\
\hline Irish Times & 32.62 & -.03 & 20.23 & -.03 & 20.72 & -.02 \\
\hline Journal.ie & 32.32 & -.02 & 0 & NA & 32.32 & -.02 \\
\hline TV3 News & 25.62 & .03 & 23.38 & .04 & 5.49 & -.03 \\
\hline Newstalk & 20.83 & .01 & 18.38 & .01 & 5.55 & -.02 \\
\hline BreakingNews.ie & 19.33 & -.03 & 0 & NA & 19.33 & -.03 \\
\hline Irish Examiner & 15.49 & -.02 & 9.44 & .00 & 10.44 & .00 \\
\hline Irish Daily Mail & 14.49 & .04 & 9.04 & .05 & 7.79 & .05 \\
\hline Yahoo! News & 11.99 & .00 & 0 & NA & 11.99 & .00 \\
\hline The Sunday Times & 11.84 & -.03 & 9.54 & -.03 & 3.45 & -.03 \\
\hline Irish Mirror & 11.49 & -.01 & 6.99 & -.01 & 6.24 & -.03 \\
\hline Her.ie/joe.ie & 10.93 & -.09 & 0 & NA & 10.93 & -.09 \\
\hline HuffPost & 10.34 & -.09 & 0 & NA & 10.34 & -.09 \\
\hline Irish Daily Sun & 9.09 & -.01 & 7.34 & .01 & 2.70 & -.07 \\
\hline UTV Ireland News & 8.64 & -.02 & 7.04 & .00 & 2.50 & -.07 \\
\hline MSN News & 8.54 & -.03 & 0 & NA & 8.54 & -.03 \\
\hline Evening Herald & 7.99 & .03 & 5.69 & .04 & 3.10 & .00 \\
\hline Sunday World & 7.89 & -.01 & 6.09 & .03 & 2.80 & $-/ .08$ \\
\hline BuzzFeed News & 7.44 & -.12 & 0 & NA & 7.44 & -.12 \\
\hline Irish Daily Star & 6.44 & -.01 & 4.60 & -.07 & 2.45 & .03 \\
\hline The Sunday Business Post & 5.05 & .01 & 4.05 & .03 & $<2$ & NA \\
\hline dailyedge.ie/The42/Fora.ie & 4.65 & -.09 & 0 & NA & 4.65 & -.09 \\
\hline Vice News & 2.40 & -.13 & 0 & NA & 2.40 & -.13 \\
\hline Today FM & - & - & 20.08 & -.01 & - & - \\
\hline TG4 News & - & - & 3.35 & -.06 & - & - \\
\hline
\end{tabular}


Table 10. Italy news outlets included

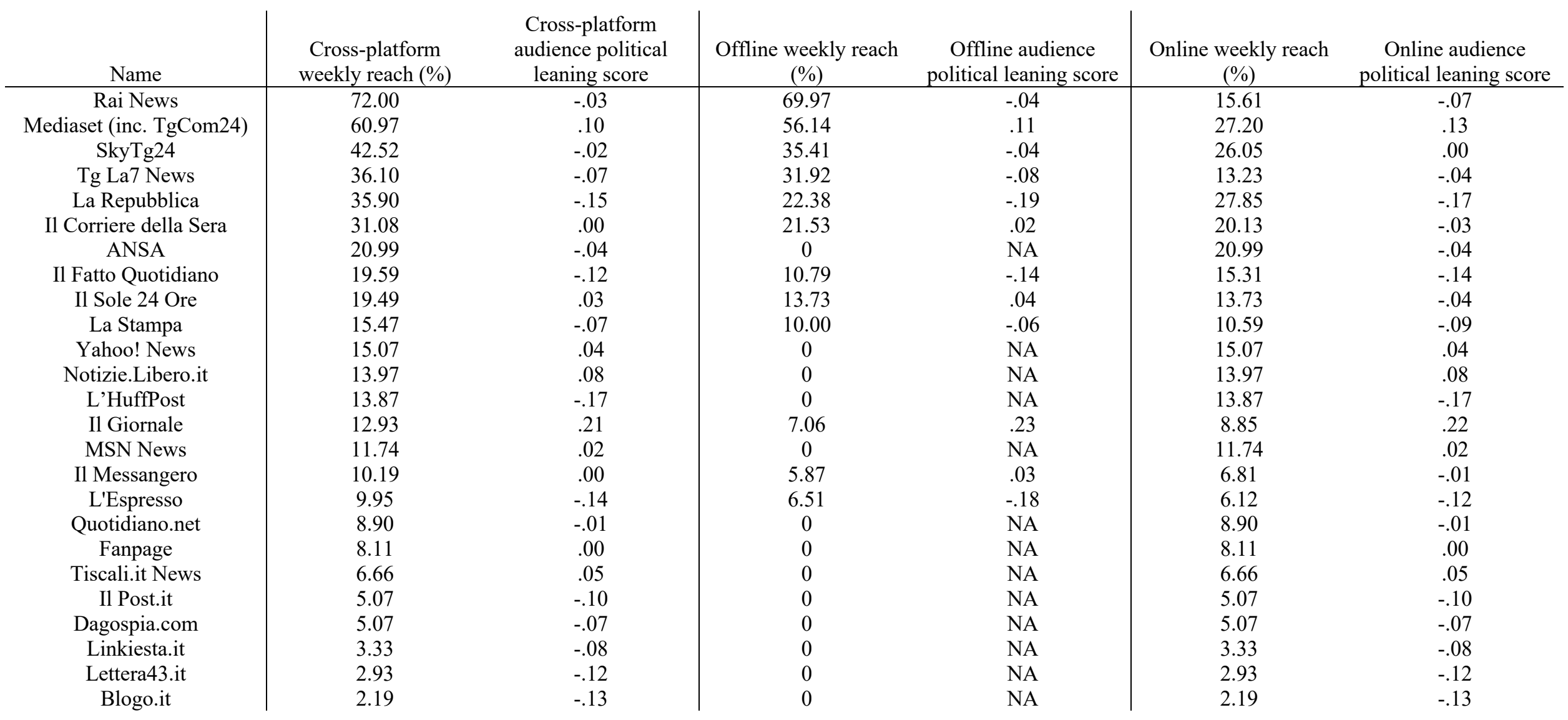


Table 11. Netherlands news outlets included

\begin{tabular}{|c|c|c|c|c|c|c|}
\hline Name & $\begin{array}{c}\text { Cross-platform } \\
\text { weekly reach }(\%)\end{array}$ & $\begin{array}{c}\text { Cross-platform } \\
\text { audience political } \\
\text { leaning score }\end{array}$ & $\begin{array}{c}\text { Offline weekly reach } \\
(\%)\end{array}$ & $\begin{array}{c}\text { Offline audience } \\
\text { political leaning } \\
\text { score }\end{array}$ & $\begin{array}{c}\text { Online weekly reach } \\
(\%)\end{array}$ & $\begin{array}{c}\text { Online audience } \\
\text { political leaning } \\
\text { score }\end{array}$ \\
\hline NOS & 74.73 & -.01 & 70.44 & -.02 & 29.46 & -.03 \\
\hline RTL & 41.18 & .05 & 33.94 & .06 & 16.35 & .05 \\
\hline $\mathrm{Nu}$ & 37.84 & .02 & 0 & NA & 37.84 & .02 \\
\hline De Telegraaf & 33.80 & .08 & 19.49 & .12 & 24.42 & .10 \\
\hline Algemeen Dagblad & 26.52 & -.01 & 15.70 & .01 & 18.64 & .00 \\
\hline SBS & 22.43 & .02 & 20.24 & .01 & 5.63 & .07 \\
\hline Metro & 16.90 & -.03 & 14.56 & -.03 & 4.93 & .00 \\
\hline de Volkskrant & 16.10 & -.14 & 10.51 & -.15 & 10.42 & -.17 \\
\hline NRC Handelsblad (inc. Next) & 8.77 & -.06 & 5.14 & -.05 & 5.83 & -.08 \\
\hline MSN News & 7.63 & -.03 & 0 & NA & 7.63 & -.03 \\
\hline Geen Stijl & 7.03 & .19 & 0 & NA & 7.03 & .19 \\
\hline Trouw & 6.78 & -.11 & 4.24 & -.12 & 3.44 & -.11 \\
\hline Netherlands Dagblad & 5.14 & -.06 & 3.14 & -.08 & 2.54 & -.05 \\
\hline Het Financieele Dagblad & 4.09 & .12 & 2.14 & .09 & 2.74 & .19 \\
\hline Yahoo! News & 2.94 & .04 & 0 & NA & 2.94 & .04 \\
\hline De Correspondent & 2.29 & -.09 & 0 & NA & 2.29 & -.09 \\
\hline
\end{tabular}


Table 12. Poland news outlets included

\begin{tabular}{|c|c|c|c|c|c|c|}
\hline Name & $\begin{array}{c}\text { Cross-platform } \\
\text { weekly reach }(\%)\end{array}$ & $\begin{array}{l}\text { Cross-platform } \\
\text { audience political } \\
\text { leaning score }\end{array}$ & $\begin{array}{c}\text { Offline weekly reach } \\
(\%)\end{array}$ & $\begin{array}{c}\text { Offline audience } \\
\text { political leaning score }\end{array}$ & $\begin{array}{c}\text { Online weekly reach } \\
(\%)\end{array}$ & $\begin{array}{c}\text { Online audience } \\
\text { political leaning score }\end{array}$ \\
\hline TVN News & 64.48 & -.07 & 56.63 & -.08 & 37.21 & -.08 \\
\hline Onet.pl News & 51.86 & .00 & 0 & NA & 51.86 & .00 \\
\hline WP.pl News & 45.90 & .02 & 0 & NA & 45.90 & .02 \\
\hline RMF FM & 44.51 & -.02 & 40.24 & -.02 & 16.05 & .02 \\
\hline Polsat News & 44.46 & -.04 & 41.78 & -.04 & 12.22 & -.05 \\
\hline TVP News & 42.28 & .14 & 37.61 & .14 & 18.08 & .20 \\
\hline Radio Zet & 33.98 & -.03 & 30.20 & -.03 & 10.83 & -.05 \\
\hline Gazeta Wyborcza & 30.25 & -.09 & 22.40 & -.10 & 19.32 & -.10 \\
\hline Interia.pl News & 29.16 & .00 & 0 & NA & 29.16 & .00 \\
\hline Fakt & 27.77 & -.04 & 16.64 & -.01 & 18.18 & -.06 \\
\hline Gazeta.pl & 23.65 & -.05 & 0 & NA & 23.65 & -.05 \\
\hline Newsweek Polska & 16.74 & -.10 & 10.73 & -.11 & 11.08 & -.10 \\
\hline Dziennik Gazeta Prawna & 15.31 & -.01 & 8.00 & -.01 & 10.58 & -.02 \\
\hline Nasze Miasto & 13.61 & .02 & 6.61 & -.02 & 9.84 & .03 \\
\hline Super Express & 13.41 & .01 & 11.03 & .03 & 4.52 & -.04 \\
\hline Polskie Radio & 12.92 & .06 & 9.69 & .04 & 5.47 & .13 \\
\hline Polityka & 12.07 & -.08 & 8.50 & -.09 & 6.36 & -.06 \\
\hline Wprost & 11.8 & -.02 & 7.30 & -.06 & 5.76 & .07 \\
\hline Rzeczpospolita & 11.33 & .03 & 8.64 & .02 & 4.86 & .04 \\
\hline Money.pl & 11.33 & .02 & 0 & NA & 11.33 & .02 \\
\hline Przeglad Sportowy & 11.22 & .09 & 7.45 & .09 & 6.76 & .08 \\
\hline Sport.pl & 10.13 & .06 & 0 & NA & 10.13 & .06 \\
\hline Bankier.pl & 8.50 & .00 & 0 & NA & 8.50 & .00 \\
\hline Nasz Dziennik & 6.26 & .27 & 3.88 & .27 & 3.38 & .29 \\
\hline Niezalenza.pl & 6.17 & .27 & 0 & NA & 6.17 & .27 \\
\hline Dziennik.pl & 4.92 & .14 & 0 & NA & 4.92 & .14 \\
\hline Natemat.pl & 4.77 & -.01 & 0 & NA & 4.77 & -.01 \\
\hline MSN News & 4.42 & .02 & 0 & NA & 4.42 & .02 \\
\hline Gosc Niedzielny & 4.12 & .26 & 3.03 & .31 & 2.13 & .23 \\
\hline Wpolityce.pl & 3.97 & .22 & 0 & NA & 3.97 & .22 \\
\hline Yahoo! News & 2.48 & .04 & 0 & NA & 2.13 & .04 \\
\hline Gazeta Polska Codziennie & - & - & 3.38 & .21 & - & - \\
\hline Angora & - & - & 12.32 & -.11 & - & - \\
\hline W Sieci & - & - & 6.26 & .25 & - & - \\
\hline
\end{tabular}


Tok FM

VOX FM

Do Rzeczy

Radio Maryja

Tygodnik Powszechny 
Table 13. UK news outlets included

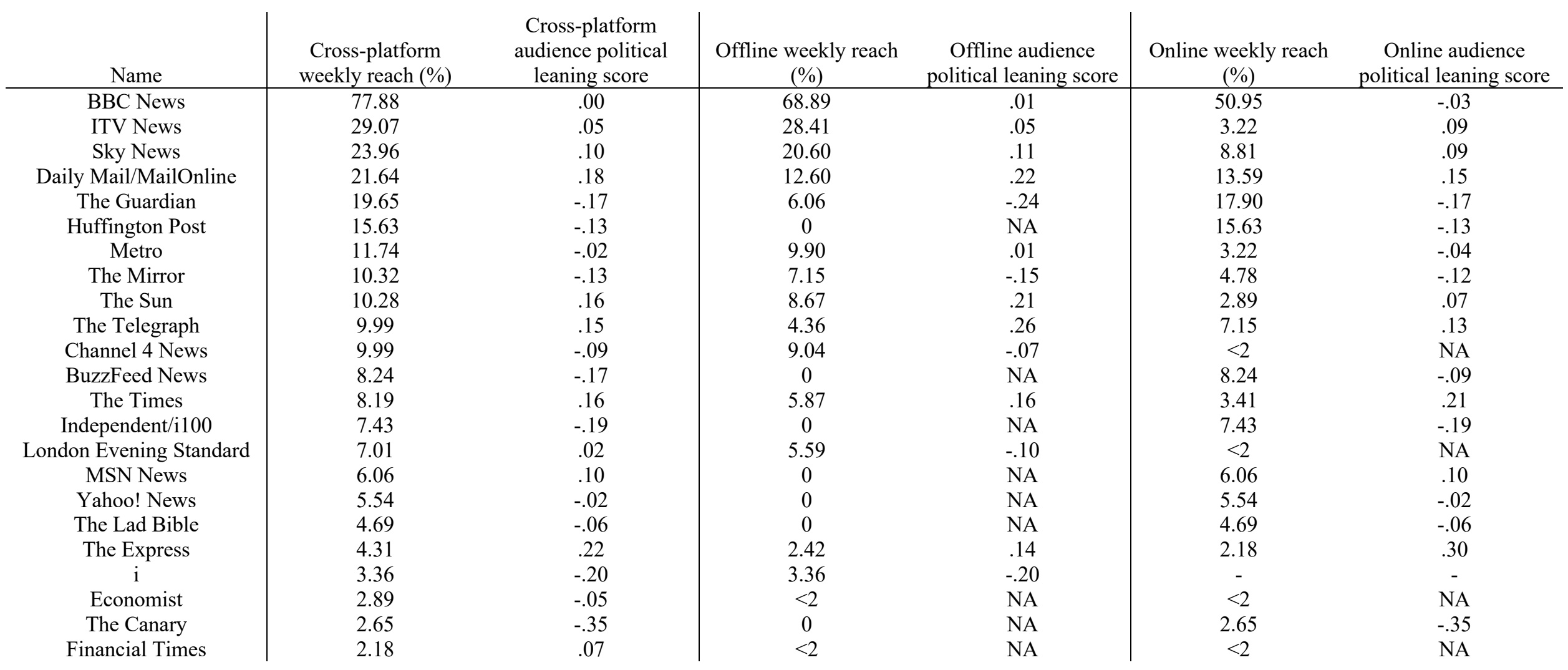


Table 14. USA news outlets included

\begin{tabular}{|c|c|c|c|c|c|c|}
\hline Name & $\begin{array}{c}\text { Cross-platform } \\
\text { weekly reach }(\%)\end{array}$ & $\begin{array}{l}\text { Cross-platform } \\
\text { audience political } \\
\text { leaning score }\end{array}$ & $\begin{array}{c}\text { Offline weekly reach } \\
(\%)\end{array}$ & $\begin{array}{c}\text { Offline audience } \\
\text { political leaning score }\end{array}$ & $\begin{array}{c}\text { Online weekly reach } \\
(\%)\end{array}$ & $\begin{array}{c}\text { Online audience } \\
\text { political leaning score }\end{array}$ \\
\hline Fox News & 39.53 & .24 & 34.51 & .27 & 21.11 & .28 \\
\hline $\mathrm{CNN}$ & 34.42 & -.15 & 25.69 & -.14 & 21.07 & -.17 \\
\hline NBC News & 32.48 & -.15 & 26.88 & -.13 & 14.46 & -.22 \\
\hline ABC News & 30.98 & -.06 & 25.52 & -.03 & 11.81 & -.16 \\
\hline CBS News & 28.65 & -.06 & 24.11 & -.04 & 9.74 & -.11 \\
\hline Huffington Post & 25.17 & -.22 & 0 & NA & 25.17 & -.22 \\
\hline Yahoo! News & 24.68 & .00 & 0 & NA & 24.68 & .00 \\
\hline New York Times & 22.74 & -.25 & 9.92 & -.25 & 18.25 & -.27 \\
\hline Washington Post & 19.66 & -.24 & 6.83 & -.25 & 17.06 & -.23 \\
\hline NPR & 17.50 & -.26 & 12.60 & -.26 & 10.40 & -.32 \\
\hline USA TODAY & 16.35 & -.13 & 9.48 & -.11 & 10.49 & -.13 \\
\hline BuzzFeed News & 16.31 & -.19 & 0 & NA & 16.31 & -.19 \\
\hline MSN News & 14.06 & -.12 & 0 & NA & 14.06 & -.12 \\
\hline Wall Street Journal & 11.99 & -.08 & 5.95 & .02 & 9.08 & -.09 \\
\hline LA Times & 7.54 & -.22 & 3.17 & -.13 & 5.69 & -.25 \\
\hline Breitbart News & 7.36 & .34 & 0 & NA & 7.36 & .34 \\
\hline Occupy Democrats & 7.23 & -.38 & - & - & 7.23 & -.38 \\
\hline Vox & 6.48 & -.35 & 0 & NA & 6.48 & -.35 \\
\hline AOL News & 6.39 & .05 & 0 & NA & 6.39 & .05 \\
\hline Al Jazeera & 5.55 & -.26 & 3.79 & -.27 & 3.83 & -.30 \\
\hline Vice News & 4.23 & -.28 & 0 & NA & 4.23 & -.28 \\
\hline Infowars & 3.83 & .19 & 0 & NA & 3.83 & .19 \\
\hline Upworthy & 3.83 & -.29 & 0 & NA & 3.83 & -.29 \\
\hline Mashable & 3.39 & -.18 & 0 & NA & 3.39 & -.18 \\
\hline PBS News & - & - & 10.92 & -.22 & - & - \\
\hline
\end{tabular}




\section{References}

Bakshy, Eytan, Solomon Messing, and Lada A. Adamic. 2015. 'Exposure to Ideologically

Diverse News and Opinion on Facebook'. Science 348: 1130-32. 